\title{
Multifunctional e-spun colloidal nanofiber structures from various dispersed blends of PVA/ODA-MMT with PVP/ODA-MMT, poly(VP-alt-MA) and AgNPs incorporated polymer complexes as electro-active platforms
}

\author{
U. Bunyatova ${ }^{1}$, Z. M. O. Rzayev ${ }^{2 *}$, M. Şimşek ${ }^{2}$ \\ ${ }^{1}$ Department of Biomedical Engineering, Faculty of Engineering, Baskent University, Baglica, 06810 Ankara, Turkey \\ ${ }^{2}$ Institute of Science and Engineering, Division of Nanotechnology and Nanomedicine, Hacettepe University, \\ 06800 Ankara, Turkey
}

Received 6 November 2015; accepted in revised form 23 February 2016

\begin{abstract}
This work presented a new approach to fabricate polymer nanocomposites films with nanofiber structures from solution blends of poly(vinyl alcohol) + octadecyl amine-montmorillonite (ODA-MMT) (matrix) with poly(N-vinylpyrrolidone) + ODA-MMT (partner-1), poly(N-vinylpyrrolidone-alt-maleic anhydride) ((poly(VP-alt-MA)) + (ODA-MMT) (partner-2) and their silver (Ag)-carrying polymer complexes by electrospinning. Chemical and physical structures, surface morphologies, thermal behaviors, electrical conductivity and thermal resistance parameters of nanofiber structures were investigated. Poly(VP-alt-MA) was used both as a crosslinker and a donor of the hydrophilic groups such as $-\mathrm{COOH}$ and $-\mathrm{NH}-\mathrm{C}=\mathrm{O}$ amide from pyrrolidone ring. Reactive poly(VP-alt-MA), in situ generated Ag nanoparticles (AgNPs) and original partner polymer had an significant effect on the morphology and diameter distribution of nanofibers. High and excellent conductive behaviors were observed for the homopolymer and copolymer of VP based fiber structures, respectively. Upon successive chemical cross-linking of the nanofiber structures by reactive partner copolymer, the conductivity of nanofiber films as electro-active platforms dramatically increased to $3.90 \cdot 10^{-2} \mathrm{~S} \cdot \mathrm{cm}^{-1}$ at room temperature. Comparative analysis results also indicated that electrical properties strongly depended on the loaded reactive organoclay and in situ generated AgNPs.
\end{abstract}

Keywords: polymer composites, PVA, PVP, electrospinning, conductivity.

\section{Introduction}

Recent studies have focused on the fabrication of electrospun (e-spun) nanofibers from solution blends of various polymers and/or polymer nanocomposites as binary multifunctional matrix/partner polymer systems [1-7]. Polymer nanofibers fabricated by electrospinning method have great importance because of their unique properties, i.e. high surface area-to-volume ratio, nanoscale fiber diameter and nanoporous surface morphology $[8,9]$.
Water-soluble poly(vinyl alcohol) (PVA) has important chemical and physical properties such as filmand fiber forming, emulsifying, surfactant and adhesion. PVA containing intra- and internal hydrogen bonding hydroxyl groups easily forms network and branched structures when it reacts with other functional polymers and compounds. It is also used to fabricate unique nanofiber compositions as a matrix polymer $[10,11]$. Some properties of polymers such as thermal, mechanical, and optical properties are

$\overline{{ }^{*} \text { Corresponding author, e-mail: rzayevzmo@gmail.com }}$ (C) BME-PT 
significantly improved by adding an organoclay into a polymeric matrix $[12,13]$.

Due to their unique properties, homo- and co- polymers of N-vinyl-2-pyrrolidone (VP) have attracted considerable academic and industrial interest [14, 15]. Poly(N-vinylpyrrolidone) (PVP) receives special attention among the conjugated polymers due to its good environmental stability, easy processability and moderate electrical conductivity. The reactive pyrrolidone group of PVP easily forms complexes with many inorganic salts, synthetic or natural functional polymers, biomolecules and biomacromolecules. To synthesize alternating copolymers of VP with maleic anhydride (MA), the solution homogeneous or heterogeneous radical copolymerization is usually used by using various solvents such as benzene, toluene [16], and 1.4dioxane [17]. In our previous study [18], poly(N-vinylpyrrolidone-alt-maleic anhydride) (poly(VP-alt-MA)) was easily dissolved in water. This dissolution process was accompanied by the full hydrolysis of anhydride units and given rise to the formation of strong hydrogen bonding intermolecular fragments.

Conductivity and thermal resistance properties of solid polymer electrolytes can be improved with chemical cross-linking, grafting, graft copolymerization, functionalization of the polymer backbone and side-chains, polymer-polymer interactions and blending with other polymers and doping agents. PVA and PVP-based solid polymer electrolytes are potential materials exhibiting good charge storage capacity and dopant dependent electrical and optical properties. The conductivity of neat PVA nanofibers was reported to be $1.25 \cdot 10^{-15} \mathrm{~S} \cdot \mathrm{cm}^{-1}$ [19] compared with that of PVP $\left(7.42 \cdot 10^{-8} \mathrm{~S} \cdot \mathrm{cm}^{-1}\right)[20]$. Hatta et al. [21] observed that solvent casting PVA/PVP thin-film solid electrolytes with a composition of $80 \%$ of PVA and $20 \%$ of PVP (v/v) exhibited the highest conductivity $\left(2.2 \cdot 10^{-7} \mathrm{~S} \cdot \mathrm{cm}^{-1}\right)$. The conductivity of this system enhanced to $1.5 \cdot 10^{-4} \mathrm{~S} \cdot \mathrm{cm}^{-1}$ when $\mathrm{KOH}(40 \%)$ was added. According to Inzelt et al. [22] conductivity of functional polymer systems depend on degree of chemical charges (such as dimerization, cross-linking, and ion-pair formation) and structural properties of chosen polymer systems, i.e. chain-segmental motions, changes in surface morphology and slow relaxation. In a study, Rajeswari et al. [23] prepared solvent casting polymer blend electrolytes with different concentrations of PVA and PVP. Maximum conductivity was found
$1.58 \cdot 10^{-6} \mathrm{~S} \cdot \mathrm{cm}^{-1}$ at room temperature for 70PVA: 30PVP $(\mathrm{v} / \mathrm{v})$ ratio without any doping agents. The authors also found that the conductivity increased to $5.49 \cdot 10^{-5} \mathrm{~S} \cdot \mathrm{cm}^{-1}$ with increasing medium temperature to $100^{\circ} \mathrm{C}$.

Besides their electrical conductivities, ionic conductivity of polymer electrolytes is fundamentally due to the covalent bonding between the polymer backbones with the ionizing groups. The electron donor group in the polymer generates dissolution to the cation constituent in dopant salt and then facilitates ion separation, causing ionic hopping mechanism. Thus, it generates the ionic conductivity. Novel ionic conductive e-spun PVA-chitosan nanofiber membranes were successfully fabricated using ionic liquids by Datta et al. [24]. Laforgue et al. [25] investigated ionic conductivity of Nafion-PVA and Nafionpoly (ethylene oxide). nanofibers and found that Nafion-PVA mats were found to be more conductive than the Nafion-PEO ones. Ionic conductivities of different polymer systems were also investigated by many researches [26-28].

Recently, many efforts have focused on the design and fabrication of polymer/metal nanoparticle (like silver) complexes due to their remarkable electronic, magnetic, catalytic, thermal and optical properties [29]. Basic principle for the fabrication of silver nanoparticles (AgNPs) involves the reduction of metal salts like silver nitrate $\left(\mathrm{AgNO}_{3}\right)$ in an appropriate medium using various reducing agents and surfactants to produce colloidal suspensions integrated by nanoparticles [29-32]. Unlike elemental silver, silver salts easily dissolve in water, and they increase the rate of $\mathrm{Ag}^{+}$ion formation over that from elemental silver. Hong et al. [33] prepared PVA nanofibers by electrospinning of PVA/ $/ \mathrm{AgNO}_{3}(1 \%, \mathrm{w} / \mathrm{w})$ aqueous solutions, followed by short heat treatment. Nguyen et al. [34] successfully synthesized PVA nanofibers containing AgNPs $(2 \% \mathrm{w} / \mathrm{w})$ through a combination of microwave irradiation and electrospinning. Several studies showed that electrical and ionic conductivity of polymer electrolytes improved in the presence of silver salts [35-38]. PVP has also attracted a great deal of attention as a polymer that can stabilize in situ generated Ag nanoparticles [39, 40]. In situ formation of Ag-nanoparticles during electrospinning process of polymer-layered silicate nanocomposites and the formation of cross-linking fiber structures as colloidal electrolytes via phase separation processing have been scarcely investi- 
gated in the presence of reactive alternating copolymer of VP.

One goal of this work was to develop synthetic pathways for the fabrication of novel polymeric fiberbased electro-active nanostructures with unique selfassembled electron transfer sites via electrospinning nanotechnology. PVA, PVP and poly(VP-alt-MA) based multifunctional matrix/partner polymer systems incorporated with an organoclay and AgNPs were fabricated and characterized. Another aim of this work was to evaluate effects of structural factors, origin and fraction of partner polymers, organoclay and in situ generated AgNPs on surface morphology and conductivity properties of nanofiber films. This work described physical and covalent functionalisation of octadecyl amine intercalated MMT clay via complexing with functional polymers (PVA, PVP) and AgNPs, and chemical cross-linking and amidization reactions of poly(VP-alt-MA) as reactive copolymer with octadecyl amine. All these in situ interactions occurred in the silicate layered region. Intercalated octadecyl amine as reactive surfactant and effective compatibilizer and reactive copolymer with alternating structures played important role in the functionalization of nanofiber composites (NFCs) before (dispersing solutions) and during electrospinning process to fabricate NFCs as electro-active nanofiber platforms. The developed approach may open up new possibilities to fabricate novel electrically conductive nanomaterials and devices for various engineering, electronic and nanotechnology applications.

\section{Experimental}

\subsection{Materials}

PVA (87-89\% hydrolyzed, weight average molecular weight $\left(M_{\mathrm{w}}=31000-51000 \mathrm{~g} / \mathrm{mol}\right)$, poly $(\mathrm{N}-2-$ vinylpyrrolidone) (Bioshop-PVP504, high purity grade, average $M_{\mathrm{w}}=40000 \mathrm{Da}$ ), ODA-MMT (content of ODA surfactant-intercalant $25-30 \%$, particle size of $8-10 \mu \mathrm{m}$, bulk density of $0.41 \mathrm{~g} / \mathrm{cm}^{3}$ and crystallinity of $52.8 \%$ (by, X-ray Diffraction), and silver nitrate $\left(\mathrm{AgNO}_{3}, 99.995 \%\right.$, m.p. $202{ }^{\circ} \mathrm{C}$ with decomposition, (density) $d=4.35 \mathrm{~g} / \mathrm{cm}^{3}$ ) were purchased from Sigma-Aldrich (Germany). N-vinyl-2pyrrolidone (VP, Fluka, Germany) was purified by distillation under moderate vacuum. Maleic anhydride (MA, Aldrich, Germany) was purified by recrystallization from anhydrous benzene solution and sublimation in vacuum. Azobisisobutyronitrile
(AIBN, Fluka, Germany) as a radical initiator was recrystallized twice from methanol. All other solvents and reagents were analytical grade and used without purification. Chemical structures, compositions and assignments of the materials used in electrospinning are given in Table 1.

\subsection{Synthetic procedures}

Alternating partner copolymer of VP with MA (poly(VP-alt-MA) was prepared by radical-initiated copolymerization in the presence of AIBN as an initiator. The copolymerization was carried out in 1,4-dioxane solution into glass tube type micro reactor by using molar (1:1) monomer mixture under nitrogen flow at $65^{\circ} \mathrm{C}$. The copolymer was isolated from the resultant mixture, purified by twice precipitation in the presence of 1.4-dioxane solution with diethyl ether, and washed with benzene. After the last extraction by diethyl ether, the copolymer was isolated via centrifugation and dried at $40{ }^{\circ} \mathrm{C}$ under moderate vacuum to arrive constant weight. Synthesized poly(VP-alt-MA) had the following average characteristics: acid number of $460 \mathrm{mg} \mathrm{KOH} / \mathrm{g}$ (by alkaline titration); nitrogen content of $N=$ 7.15 mass \% (by elemental analysis); molar monomer unit ratio of $m_{1}(\mathrm{VP}) / m_{2}(\mathrm{MA})=1.12\left(m_{1}\right.$ and $m_{2}$ are relative amounts of VP and MA (in mol) in the copolymer, respectively); intrinsic viscosity of $[\eta]_{\text {in }}=$ $0.79 \mathrm{dL} / \mathrm{g}$ in deionized water at $25^{\circ} \mathrm{C}$; glass transition temperature of $T_{\mathrm{g}}=159,8^{\circ} \mathrm{C}$ (by DSC); and ${ }^{1} \mathrm{H}-\mathrm{NMR}$ spectra (in $\mathrm{CHCl}_{3}-d_{1}$ ), $\delta$ (ppm): $1.30-1.83$ $\mathrm{CH}_{2}$ (backbone), 3.56-3.95 $\mathrm{CH}$ (CH-N backbone), 1.83-2.33 $\mathrm{CH}_{2}$ and 2.95-3.54 $2 \mathrm{CH}_{2}$ (pyrrolidone ring) for VP unit and 4.08-4.45 $\mathrm{CH}$ (backbone) for anhydride unit.

PVA + ODA-MMT (3,5 mass \%) nanocomposite as a matrix polymer was prepared by dispersed solution intercalating of PVA polymer chains between organoclay galleries in pure water medium under intensive mixing up to the formation of dispersed homogeneous viscous product at $40^{\circ} \mathrm{C}$ for $3 \mathrm{~h}$. Water solutions of PVP (homopolymer) + ODA-MMT (5 mass $\%)$ and alternating copolymer poly(VP-altMA) + ODA-MMT (5 mass\%) as an intercalated partner nanocomposite were prepared by using a similar procedure. Matrix/partner polymer/ $\mathrm{AgNO}_{3}$ complexes were prepared by the addition of powder $\mathrm{AgNO}_{3}$ (1 mass\%) to the corresponding polymer solution and each complex was additionally mixed at room temperature for $1 \mathrm{~h}$. 
Table 1. Chemical structures, compositions and assignments of the materials used in electrospinning

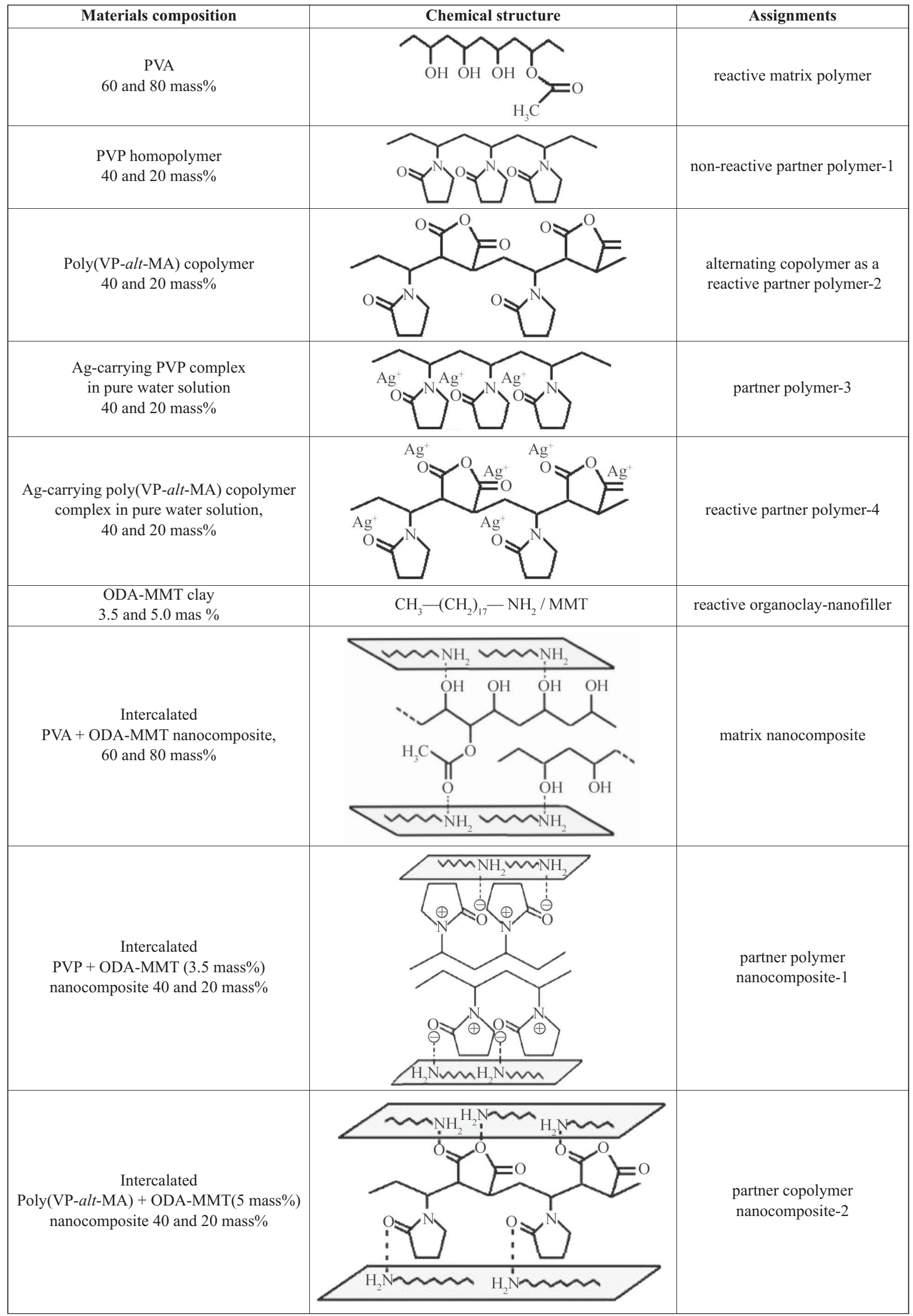




\subsection{Fabrication of nanofiber electrolytes}

Solution blends of matrix/partner polymer composites with various volume ratios in the presence and absence of silver precursor were used to fabricate polymer electrolytes with nanofiber structures by electrospinning method. Electrospinning parameters such as polymer concentration, applied voltage, tip-to-collector distance, and flow rate were optimized for each series of nanofiber composites. Randomly oriented nanofibers were obtained by collecting fibers onto an aluminum foil fixed on stationary collector. First series of e-spun nanofibers was fabricated from PVA + ODA-MMT/PVP + ODA-MMT as a matrix/partner polymer composite system and its Ag-carrying composition. For second series of nanofibers, poly(VP-alt-MA) copolymer + ODA-MMT as a partner polymer was used. Table 2 presents the composition of matrix/partner polymers, their abbreviations, and optimized electrospinning conditions.

\section{Characterization and methods}

The Fourier transfer infrared (FT-IR) spectra were recorded on a FT-IR Nicolet 510 spectrometer in the range of $4000-400 \mathrm{~cm}^{-1}$ with a resolution of $4 \mathrm{~cm}^{-1}$. XRD tests were performed with a PANANALYTICAL X-ray diffractometer equipped with a $\mathrm{CuK}_{\alpha}$ tube and Ni filter $(\lambda=1.5406 \AA)$. The XRD diffractograms were measured at the angle of reflection in the range $1-70^{\circ}$. XRD data were analyzed using the DIFFRAC-Plus EVA and High Score Plus (particle size) programs, and the patterns were identified using the ICDD PDFMaint computer reference database.

Surface morphology of nanofibers was examined by using a Field Emission Scanning Electron Micro- scope (FESEM, ZEISS SUPRA 40). All specimens were freeze-dried and coated with a thin layer of platinum before testing. Average diameters of fibers were calculated from SEM images of minimum a hundred individual fibers by using ImageJ software (NIH, Bethesda, MD) for each sample. The formation of AgNPs in fibers was visualized by a high contrast transmission electron microscope (CTEM, FEI Tecnai G2 Spirit BioTwin). Energy-dispersive X-ray spectroscopy (EDX) analysis was used to investigate the formation of AgNPs on fiber surfaces.

Thermo gravimetric (TGA) and differential scanning calorimetric (DSC) analyses were performed by using EXTRAR600 TG-DTA6300 and Diamond DSC Perkin Elmer Thermal Analyzers at a linear heating rate of $10^{\circ} \mathrm{C} / \mathrm{min}$ under nitrogen flow. Samples were measured in a sealed alumina pan with a mass of about $10 \mathrm{mg}$. The thermal degradation temperature taking into account was the temperature at onset $\left(T_{\text {onset }}\right)$ and the temperature at maximum weight loss $\left(T_{\mathrm{d}(\max )}\right)$.

Electrical conductivity and thermal resistance of nanofiber samples as solid/colloidal electrolytes were measured by using a test chamber (JANIS VPF 100 cryostat). Current through thin fiber film was recorded with a Keithley 2400 current-voltage measurement system. Square-shaped samples $\left(0.25 \mathrm{~cm}^{2}\right)$ with four contact points at the corners were prepared to carry out conductivity measurements which were done according to the van der Pauw method. Experiments were conducted in temperature range of $20-50{ }^{\circ} \mathrm{C}$ with $1{ }^{\circ} \mathrm{C}$ steps (Keithley 6487 Picoammeter/Voltage source) and pressure range of 50800 Torr (6.67 to $106.7 \mathrm{kPa}$ ). Sample temperature was monitored regularly by using a Pt 100 sensor close to the sample and measured with Lakeshore

Table 2. Compositions of matrix/partner polymer, their abbreviations, and electrospinning conditions

\begin{tabular}{|c|c|c|}
\hline \multicolumn{3}{|c|}{$\begin{array}{c}\text { PVA }(9 \%, \text { w/v) + ODA-MMT }(3.5 \%, \text { w/w)/PVP }(9 \%, \text { w/v) + ODA-MMT }(5 \%, \text { w/w) } \\
\text { [Matrix/partner] }\end{array}$} \\
\hline $\begin{array}{l}\text { Matrix/partner ratio } \\
(\mathrm{v} / \mathrm{v})\end{array}$ & Abbreviation & Electrospinning conditions \\
\hline$(6 / 4)$ & NFC-1 & $23.5 \mathrm{kV} ; 0.7 \mathrm{~mL} / \mathrm{h} ; 17 \mathrm{~cm}$ \\
\hline$(8 / 2)$ & NFC-2 & $23.5 \mathrm{kV} ; 0.7 \mathrm{~mL} / \mathrm{h} ; 15 \mathrm{~cm}$ \\
\hline$(8 / 2)+\operatorname{AgNO}_{3}(1 \%, w / w)$ & NFC-2/AgNPs & $28 \mathrm{kV} ; 0.5 \mathrm{~mL} / \mathrm{h} ; 17 \mathrm{~cm}$ \\
\hline \multicolumn{3}{|c|}{$\begin{array}{c}\text { PVA }(9 \%, \text { w/v) + ODA-MMT }(3.5 \%, \text { w/w)/poly(VP-alt-MA) }(9 \%, \text { w/v) + ODA-MMT }(5 \%, \text { w/w) } \\
\text { [Matrix/partner] }\end{array}$} \\
\hline $\begin{array}{l}\text { Matrix/partner ratio } \\
(\mathrm{v} / \mathrm{v})\end{array}$ & Abbreviation & Electrospinning conditions \\
\hline$(6 / 4)$ & NFC-3 & $23 \mathrm{kV} ; 0.7 \mathrm{~mL} / \mathrm{h} ; 15 \mathrm{~cm}$ \\
\hline$(8 / 2)$ & NFC-4 & $21 \mathrm{kV} ; 0.7 \mathrm{~mL} / \mathrm{h} ; 15 \mathrm{~cm}$ \\
\hline$(8 / 2)+\mathrm{AgNO}_{3}(1 \%, \mathrm{w} / \mathrm{w})$ & NFC-4/AgNPs & $23.5 \mathrm{kV} ; 0.7 \mathrm{~mL} / \mathrm{h} ; 17 \mathrm{~cm}$ \\
\hline
\end{tabular}


model 331-temperature controller with sensitivity of $\pm 0.1^{\circ} \mathrm{C}$. All measurements were performed with a PC through a GPIB converter card.

\section{Results and discussion}

\subsection{Synthetic pathways}

The matrix nanocomposite was fabricated by intercalating of PVA between ODA-MMT organoclay tetragonal 1:2 layers through $-\mathrm{OH} . . . \mathrm{NH}_{2}-$ complex formation of hydroxyl groups of PVA with primary amine groups of octadecylamine surfactant-intercalant. First intercalated partner nanocomposite $(\mathrm{PVP}+\mathrm{ODA}-\mathrm{MMT})$ was prepared through physical interaction $\left(-\mathrm{C}=\mathrm{O} \ldots \mathrm{NH}_{2}-\right.$ complex-formation) of carbonyl/amine groups of PVP (pyrrolidone unit) and ODA-MMT (amine), respectively. Second partner copolymer nanocomposite, poly(VP-alt-MA) + ODA-MMT, was synthesized under similar intercalating conditions. In order to obtain Ag-carrying matrix/partner nanocomposite complex, certain amount of $\mathrm{AgNO}_{3}$ was added to solution of matrix/partners nanocomposite and the resultant mixture was additionally mixed for 1 hour. To fabricate e-spun nanofibers, various solution blends of matrix/partner polymer nanocomposites at different ratios $(10 / 0,8 / 2$ and $6 / 4 \mathrm{v} / \mathrm{v})$ were used.
Synthetic pathways of nanocomposite nanofibers and chemistry of polymer-polymer covalent crosslinking are schematically represented in Figure 1. Mixing of matrix and partner polymer nanocomposite solutions in water and then the fabrication of nanofibers from different solution blends by electrospinning was accompanied by various interfacial interactions between functional groups of both polymer nanocomposites and organoclay, most likely via hydroxyl-amine, hydroxyl-amide, carbonyl-hydroxyl and carbonyl-amine hydrogen bonding, as well as silver cation-electrondonor functional groups. In the presence of homopolymer in PVP + ODA-MMT nanocomposite as a partner polymer, in situ physical interfacial interactions between functional groups of matrix ( $-\mathrm{OH}$ and $-\mathrm{C}=\mathrm{O}$ ester) and partner $(-\mathrm{NH}-\mathrm{C}=\mathrm{O}$ amide from pyrrolidone ring) polymers, organic octadecyl amine fractions, and ionized species from MMT clay were predominantly realized.

Number of physical interactions increased in the presence of poly(VP-alt-MA) + ODA-MMT as a partner copolymer due to additional presence of reactive anhydride $-\mathrm{C}=\mathrm{O}$ and carboxyl $-\mathrm{COOH}$ groups. Moreover, these reactive groups provided effective grafting (amidization of anhydride unit with octadecyl amine) and covalent cross-linking (esterification
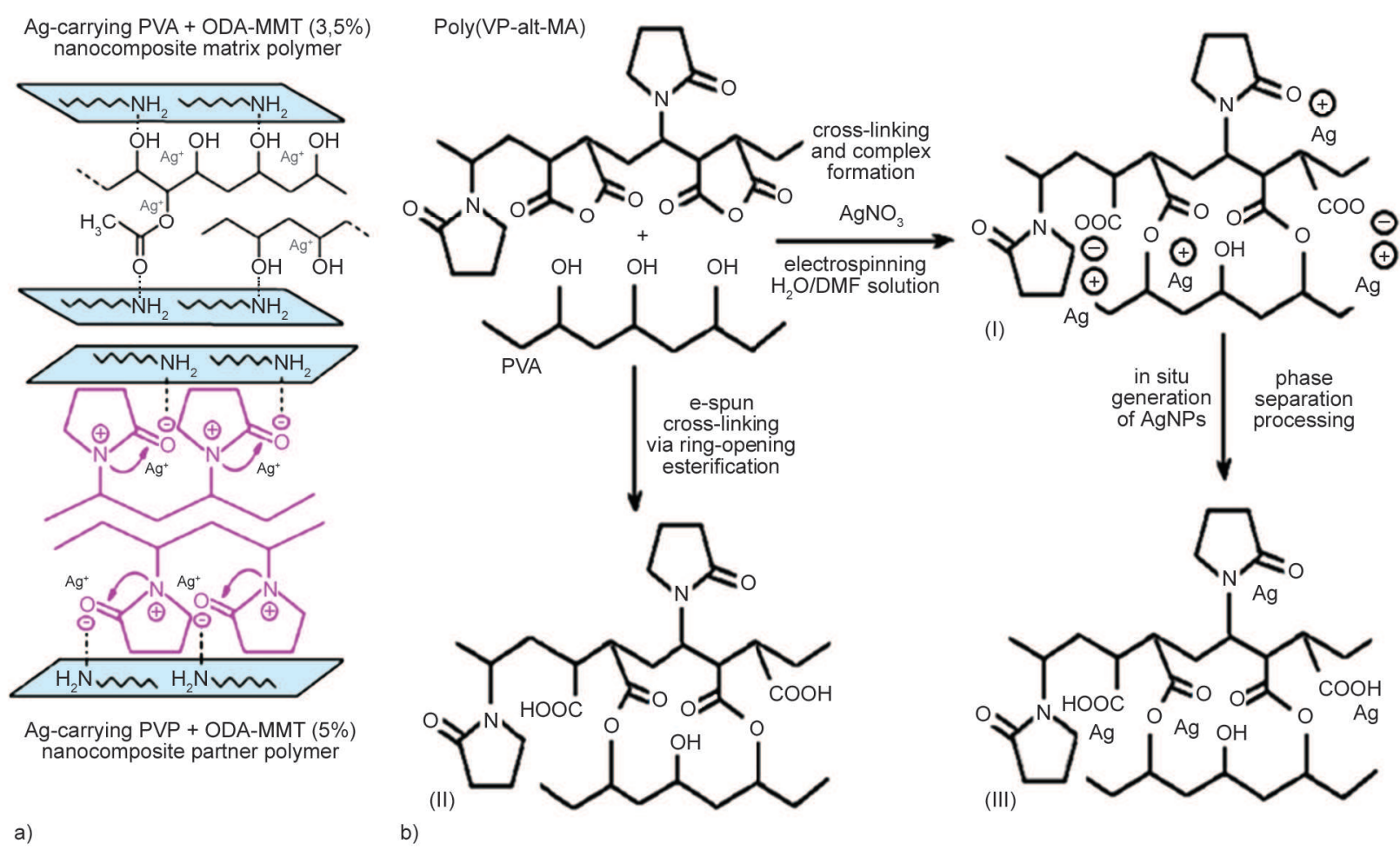

Figure 1. a) The synthetic pathways to fabricate nanocomposites and nanofibers, b) chemistry of covalent cross-linking matrix and partner polymer chains via ring-opening esterification: (I) Ag-carrying polymer complex, (II) crosslinked structure and (III) in situ generated AgNPs onto polymer chains 
of anhydride unit with hydroxyl group of matrix polymer) between matrix-partner polymer chains. The observed covalent in situ interactions were important structural factors to enhance the stable ion charged sites. Therefore the electrical conductivity of nanofiber structures significantly increased. Polymerpolymer, polymer-organoclay and polymer-silver forces altered the hydrophilic/hydrophobic balance and controlled the phase separation process, resulting in the formation of fiber webs with unique distributed cross-section fibrous morphology. Furthermore, the phase separation process also accelerated significantly with the addition of silver ions through the formation of stable complexes with anion active functional groups as ion transfer sites onto matrixpartner polymer chains. It was demonstrated that the fabricated multifunctional electrolytes incorporated with organoclay and AgNPs exhibited unique dispersed silver nanoparticles onto fiber surface. Silver cations turned into in situ generated AgNPs without the use of dominated annealing and UV-irradiation procedures throughout phase separation processing during electrospinning. This observation can be described as a simple and effective method to prepare AgNPs during electrospinning processing.

\subsection{Chemical structures of nanofiber composites}

Figure 2 shows the IR spectra of the fabricated polymer nanofiber electrolytes. Broad absorption bands around $3314-3293 \mathrm{~cm}^{-1}$ in spectra of all fiber compositions were associated with hydrogen-bonded $\mathrm{OH}$ and $\mathrm{NH}_{2}$ stretching from PVA and octadecyl amine chains. Visible shift of this peak to the lower frequency region (NFC-2/AgNPs) can be explained by the increase of hydrogen bonding and complexformation with AgNPs. Weak C-O-H band appeared around $1320 \mathrm{~cm}^{-1}$. These observations successfully confirmed the formation of cross-linking structure via ring-opening inter-macromolecular esterification of maleic anhydride/carboxyl groups with hydroxyl groups of matrix PVA chains during electrospinning. Pyrrolidone unit (secondary amide) of partner PVP polymer was characterized with the following bands: $\mathrm{C}=\mathrm{O}$ stretching around $1732 \mathrm{~cm}^{-1}$ for amide-I band, $\mathrm{NH}$ stretching around $1654 \mathrm{~cm}^{-1}$ for amide-II band, and $\mathrm{C}-\mathrm{N}$ stretching between $1421-1426 \mathrm{~cm}^{-1}$ for amide-III band. $\mathrm{NH}_{2}$ deformation and wagging bands between $848-855 \mathrm{~cm}^{-1}$ and

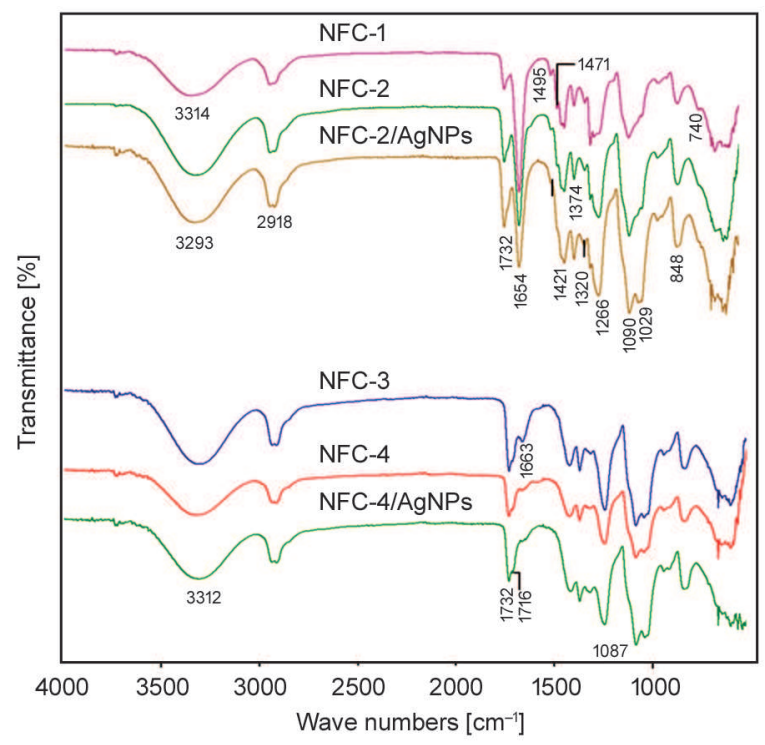

Figure 2. FT-IR spectra of NFC-1, NFC-2, and NFC-2/ AgNPs nanofibers from PVA + ODA-MMT/PVP + ODA-MMT; and NFC-3, NFC-4, and NFC-4/ AgNPs nanofibers from PVA + ODA-MMT/poly (VP-alt-MA) + ODA-MMT

at $1495 \mathrm{~cm}^{-1}$ can be attributed to octadecyl amine complex from ODA-MMT clay, and peak around $740 \mathrm{~cm}^{-1}$ can be related to $-\mathrm{CH}_{2}-$ rocking band in an octadecyl chain. $\mathrm{C}-\mathrm{H}$ stretching bands around $2918 \mathrm{~cm}^{-1}$ were related to $\mathrm{CH}, \mathrm{CH}_{2}$ and $\mathrm{CH}_{3}$ groups from octadecyl group and backbone chains, and their bending bands appeared at 1471 and $1374 \mathrm{~cm}^{-1}$. Characteristic broad peaks between $1255-1272 \mathrm{~cm}^{-1}$ and around $1090 \mathrm{~cm}^{-1}$ were due to $\mathrm{C}-\mathrm{O}$ and $\mathrm{C}-\mathrm{O}-\mathrm{C}$ absorption bands from carboxyl and ester carboxylate groups, respectively. Silicate band appeared at $1029 \mathrm{~cm}^{-1}$ (Si-O-Si). The following absorption bands were observed in FTIR spectra of nanofiber composites containing poly(VP-alt-MA)+ODAMMT: Absence of characteristic absorption bands from anhydride units of copolymer (1776 and $1840 \mathrm{~cm}^{-1}$ ) [41] in the carbonyl region of the nanofiber's spectra and appearance of $\mathrm{C}=\mathrm{O}$ and $\mathrm{C}-$ $\mathrm{O}-\mathrm{C}$ bands from ester groups (1732 and $1087 \mathrm{~cm}^{-}$ ${ }^{1}$ ), and maleate $-\mathrm{COOH}\left(1716\right.$ and $1663 \mathrm{~cm}^{-1}$ for $\mathrm{C}=\mathrm{O}$ and $3312 \mathrm{~cm}^{-1}$ for hydrogen bonded $\mathrm{OH}$ in carboxyl group) were observed.

\subsection{Physical structures of nanofiber composites}

Physical structures of nanofibers were determined by XRD method. Obtained XRD patterns and peak reflection parameters are given in Figure 3. The 
well-known Scherrer equation (Equation (1)) was used to calculate particle sizes ( $\tau_{\mathrm{sh}}$, the mean thickness) in fiber structures [42]:

$\tau_{\mathrm{sh}}=\frac{K_{\mathrm{sh}} \lambda}{\beta \cos \theta}$

where $\tau$ is the mean size of the ordered (crystalline) domains, which may be smaller or equal to the grain size; $K$ is a Scherrer constant $\left(K_{\mathrm{sh}}\right.$ of 0.89$) ; \lambda$ is the $\mathrm{X}$-ray wavelength $(\lambda=1.5406 \mathrm{~nm}) ; \beta$ is the line broadening at half the maximum intensity (FWHM), after subtracting the instrumental line broadening, in radians. The Bragg equation (Equation (2)) was used to calculate the interlayer spacing $(d)$ :

$n \lambda=2 d \sin \theta$

where $n$ is the order of reflection and $2 \theta$ is the angle of reflection.

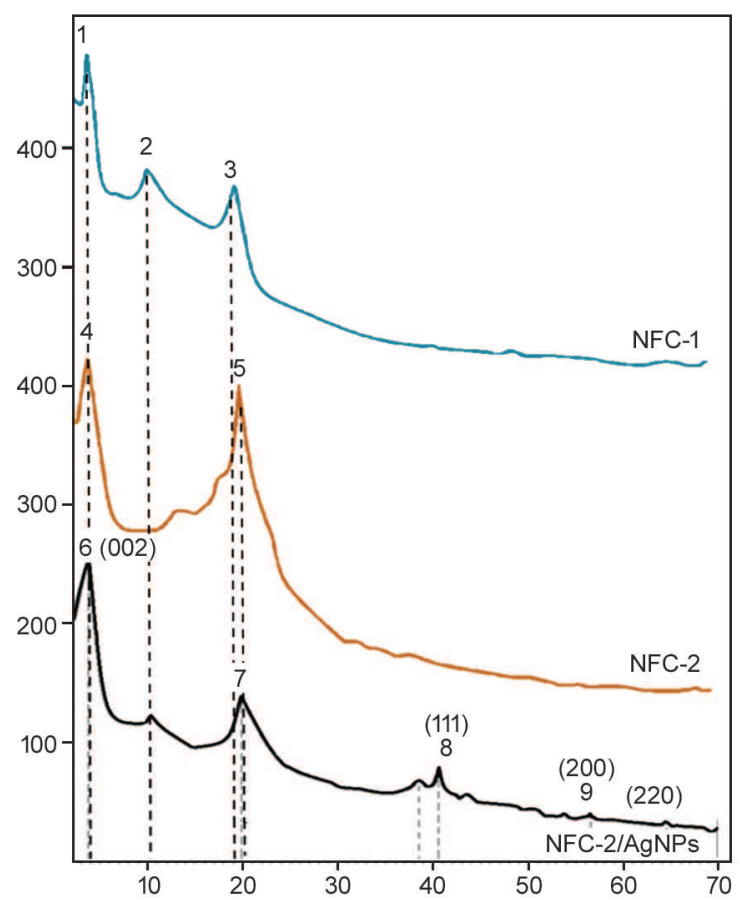

\begin{tabular}{|c|c|c|c|c|c|c|}
\hline & \multicolumn{6}{|c|}{ X-ray reflection parameters } \\
\hline & Peak & $2 \theta$ & $\begin{array}{c}\text { D-spacing } \\
{[\AA]}\end{array}$ & $\begin{array}{l}\text { Intensity } \\
\text { (Counts) }\end{array}$ & $\begin{array}{c}\text { FWHM } \\
{\left[{ }^{\circ} 2 \theta\right]}\end{array}$ & $\begin{array}{c}\text { Particle size } \\
{[\AA]}\end{array}$ \\
\hline \multirow{3}{*}{ NFC-1 } & 1 & 3.81 & 23.175 & 100.00 & 0.444 & 115.68 \\
\hline & 2 & 10.09 & 8.765 & 35.58 & 0.933 & 96.60 \\
\hline & 3 & 19.55 & 4.537 & 28.74 & 0.090 & 14260 \\
\hline \multirow{2}{*}{ NFC-2 } & 4 & 3.68 & 23.963 & 40.16 & 0.090 & 21720 \\
\hline & 5 & 19.89 & 4.459 & 100.00 & 0.948 & 73.835 \\
\hline \multirow{4}{*}{$\begin{array}{l}\text { NFC-2/ } \\
\text { AgNPs }\end{array}$} & 6 & 3.68 & 23.963 & 51.51 & 0.090 & 21720 \\
\hline & 7 & 19.75 & 4.491 & 100.00 & 1.137 & 60.96 \\
\hline & 8 & 40.51 & 2.224 & 50.81 & 0.758 & 98.15 \\
\hline & 9 & 56.57 & 1.625 & 14.24 & 1.137 & 68.21 \\
\hline
\end{tabular}

Figure 3. XRD patterns and peak reflection parameters of NFC-1, NFC-2, and NFC-2/AgNPs nanofibers
The figure shows polymer composites exhibited semicrystalline structure since they contain crystalline and amorphous structure. Crystalline peaks around $20^{\circ} 2 \theta$ angle belonged to PVA, corresponding to (110) reflection. The intensity of the XRD patterns decreased since the amorphous nature of PVA increased with the addition of PVP. The increase in the amorphous nature of polymer electrolytes causes a reduction in the energy barrier to the segmental motion of the polymer electrolyte resulting in high ionic conductivity [23].

Pristine ODA/MMT clay exhibits a strong peak at $2 \theta=4.45^{\circ}$ with a distance ( $d$-spacing) of $19.93 \AA$ (002) between two tetragonal layers and several crystallite peaks related to the intermolecular interactions of octadecyl amine and hydroxyl groups from the clay structure via $-\mathrm{Si}-\mathrm{OH} . . . \mathrm{NH}_{2}-$ hydrogen bonding at edges [43]. The position of reflection peak at $4.45^{\circ} 2 \theta$ shifted to lower region (3.81 and $3.68^{\circ}$ $2 \theta$ ) with an increase in $d$-spacing from $19.93 \AA$ (002) to 23.17 and $23.96 \AA$ for ODA-MMT (NFC-1 and NFC-2). This observation indicated the formation of nanofibers with low degree of intercalation due to the domination of the colloidal structures in NFCs. The number of crystalline peaks increased with incorporating of AgNPs because of the formation of the characteristic X-ray reflections from crystallinity peaks in XRD patterns. The observed weak peaks at $2 \theta$ angles $\left(38.4,56.5\right.$ and $\left.64.6^{\circ}\right)$ can be related to the (111), (200) and (220) planes of in situ generated crystalline AgNPs [44]. These results indicated that silver salts successfully turned into in situ generated AgNPs during electrospinning process. Relatively low crystallinity was observed in NFCs consisting 60-80 mass $\%$ of PVA compared with pristine PVA polymer (around 30-50\%) [45]. This fact can be explained by colloidal state of silicate region (broad peak with higher amorphous area) in fiber compositions and tendency of nanofibers to absorption and swelling in applied aqueous medium. The presence of microparticles with size of $2.172 \mu \mathrm{m}$ confirmed the above mention proposal.

\subsection{Morphology of nanofiber electrolytes}

The phase separation process during electrospinning and properties of fabricated nanofibers strongly depends on the applied electrospinning parameters, matrix-partner polymer compatibility, chemical and physical structural factors, and various interactions such as hydrogen bonding, complex formation, and 
different chemical reactions between functional groups of both polymers. Morphological characteristics and diameters of nanofibers from NFC-1, NFC-2, and NFC-2/AgNPs are given in Figure 4a-c. It can be clearly seen that all fibers exhibit porous surface morphology. Solvent evaporation happens mainly from the surface of polymer jet. In addition,

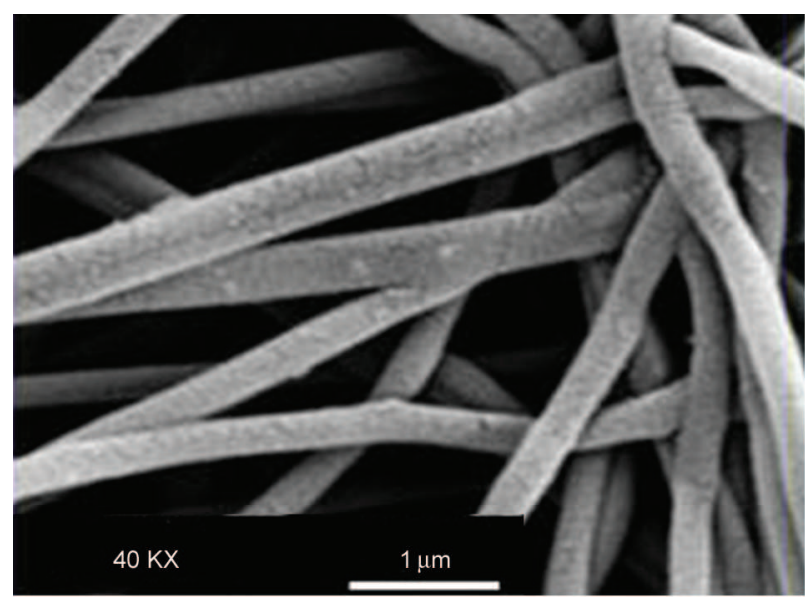

a)

NFC-1

$294 \pm 53 \mathrm{~nm}$

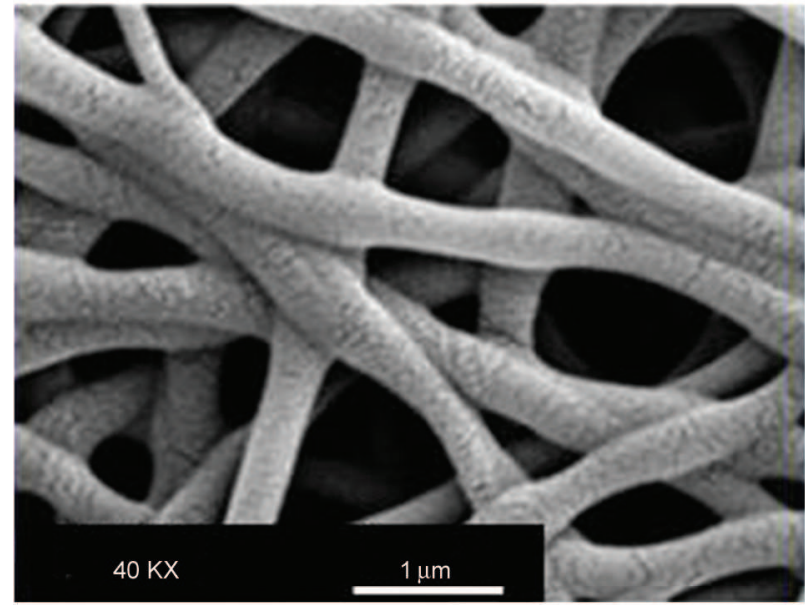

b)

NFC-2

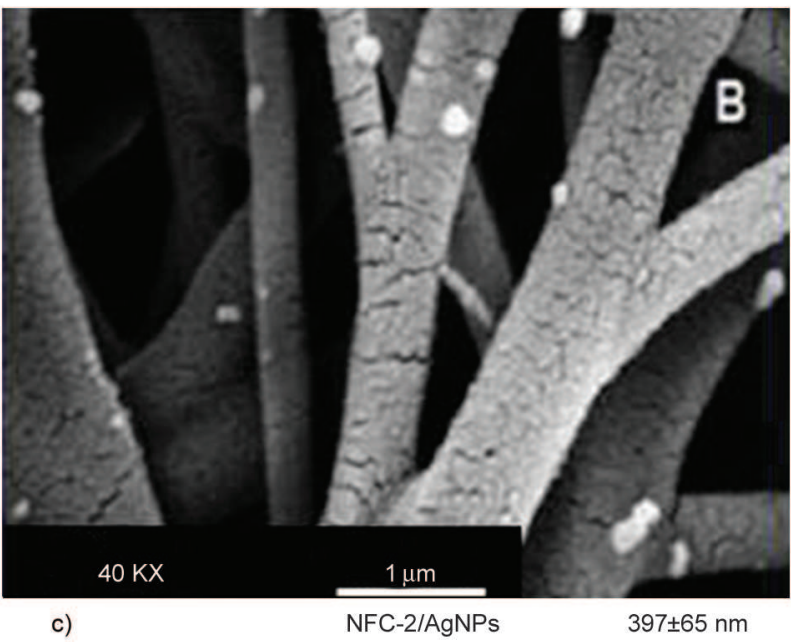

the diffusion rate of solvent molecules from the core to the surface is usually lower than that of the solvent evaporation. The diffusion of water molecules from the jet to the atmosphere changes the jet composition, as well. Thus, the variation of the jet composition can lead to the formation of heterogeneous regions within the jet. We concluded that PVP molecules limit

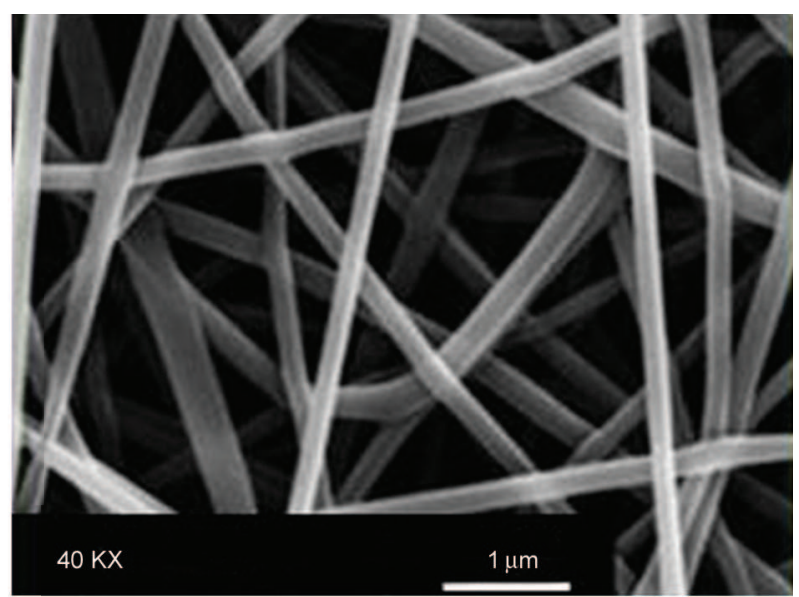

d)

NFC-3

$240 \pm 38 \mathrm{~nm}$

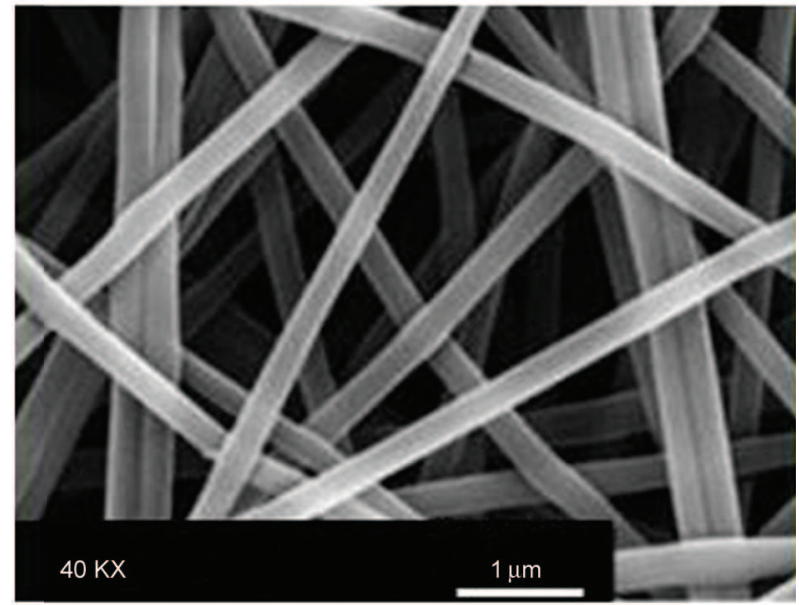

e)

NFC-4 $315 \pm 44$ nm

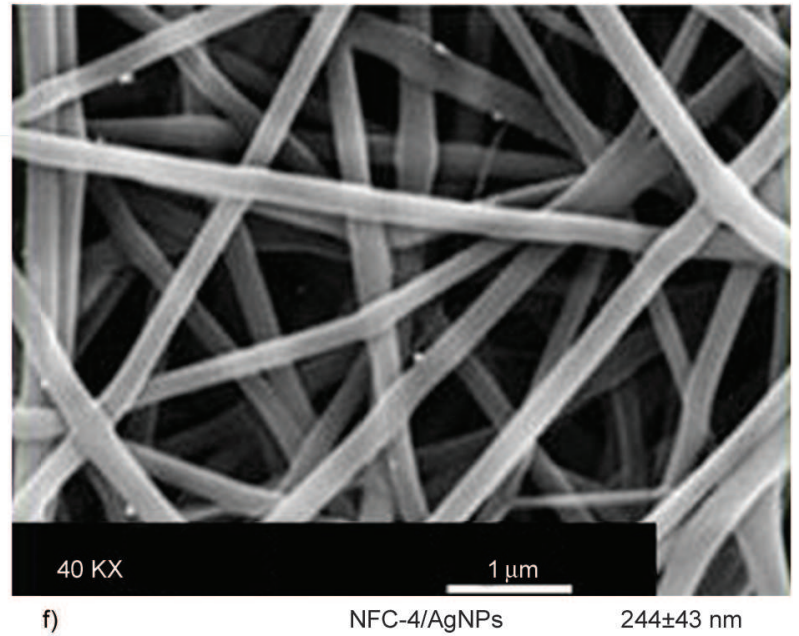

Figure 4. SEM morphology images and diameter distribution of a) NFC-1, b) NFC-2, and c) NFC-2/AgNPs, d) NFC-3, e) NFC-4, and f) NFC-4/AgNPs nanofibers 
the ability of the solution to fill the pores during evaporation of the condensed moisture on the fibers and result in a porous fiber. Whereas mean diameters of the fibers were not affected significantly by fiber composition, diameter distribution improved in the presence of in situ generated AgNPs (Figure 4c). In this system, silver salts easily transformed to nanoparticle form, which essentially accelerated the phase separation process and improved the distribution and size parameters of nanofibers. Silver salts into polymer solution being ejected not only transformed easily into silver particles during fiber formation, but also were well-dispersed onto the fiber surfaces due to increase of the surface area of the fibers (white points in Figure 4c).

Unlike PVP homopolymer containing nano-porous nanofibers, the nanofibers containing reactive poly (VP-alt-MA) copolymer had non-porous and smooth surface morphology due to their covalent bonding network structures which essentially prevented the fast diffusion and elimination of water molecules from inside area of fibers during electrospinning (Figure $4 d-f)$. Fine surface morphology also indicated that matrix and partner polymer show good compatibility. In this composition, the mobility of PVA chains in colloidal/amorphous region was restricted by the presence of the covalent cross-linked fragments in fiber structures. An increase in partner polymer fraction essentially improved fiber diameter distribution and caused the formation of approximately

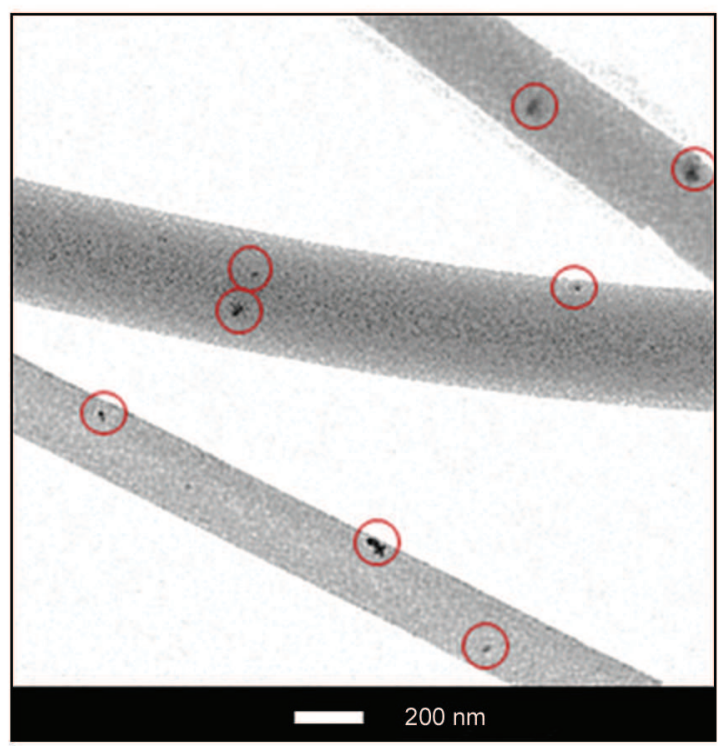

a) homogenous fiber size with maximum fraction of $82 \%$. In situ generated AgNPs had significant effect on the morphology and diameter distribution parameters of the fibers, as well (Figure 4f). When comparing with the fibers fabricated without silver precursor (Figure 4e), the diameter of NFC-4/AgNPs fibers not only dramatically decreased from 315 to $244 \mathrm{~nm}$, but also their diameter distribution improved (Figure 4f). TEM images reveal that AgNPs around 20-40 nm were also successfully formed into the fiber structure (Figure 5a). EDX analysis confirmed the formation of AgNPs on the surfaces (Figure 5b).

\subsection{Thermal behaviors of nanofiber structures consisting poly(VP-alt-MA) copolymer}

Results of TGA and DTG analyses are given in Figure 6. The TGA-DTG curves of nanofiber film composites showed two steps degradations: $T_{\mathrm{d}(\max )}=$ $330.3^{\circ} \mathrm{C}$ (first step), $437.1^{\circ} \mathrm{C}$ (second step), and total weight loss $=81.31 \%$ for NFC-3 (Figure 7a); $T_{\mathrm{d}(\max )}=316.5^{\circ} \mathrm{C}$ (first step), $433.8^{\circ} \mathrm{C}$ (second step), and total weight loss $=88.05 \%$ for NFC-4 (Figure 6b). NFC-4/AgNPs nanofiber composite was also exhibited two-stage degradation with different mechanism: $200.7^{\circ} \mathrm{C}$ (first step), $324.2^{\circ} \mathrm{C}$ (second step), and total weight loss $=73.89 \%$ (Figure $6 \mathrm{c}$ ). An increase in the fraction of partner copolymer from $20 \%$ to $40 \%$ increased thermal stability. NFC-4/ AgNPs also showed high thermal stability. High ther-

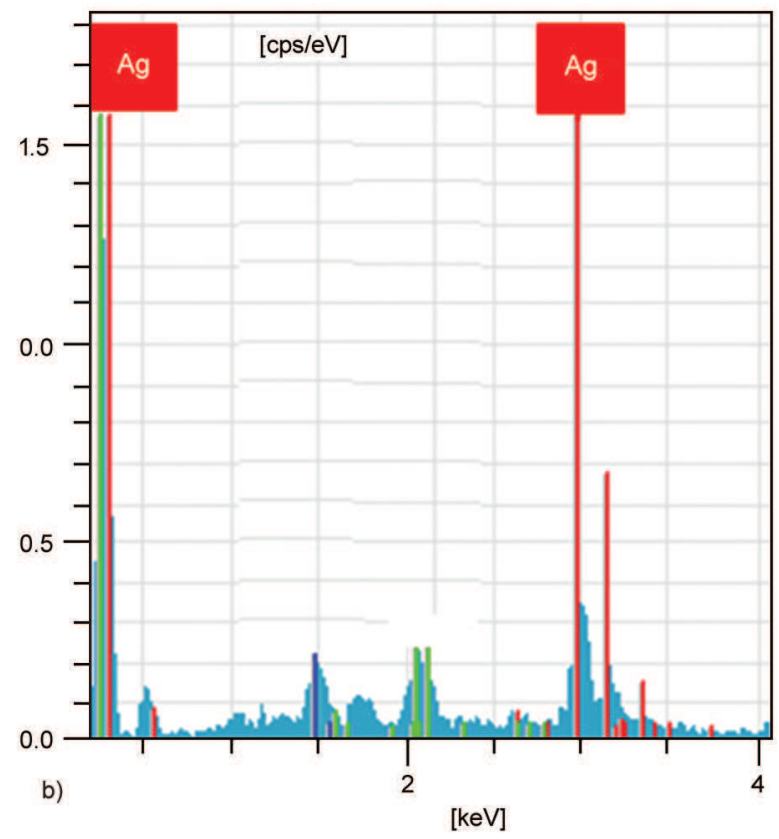

Figure 5. TEM images of (a) NFC-2/AgNPs (Black points in red circles indicate AgNPs with nano-sizes around 20-40 nm) and (b) EDX analysis of AgNPs 


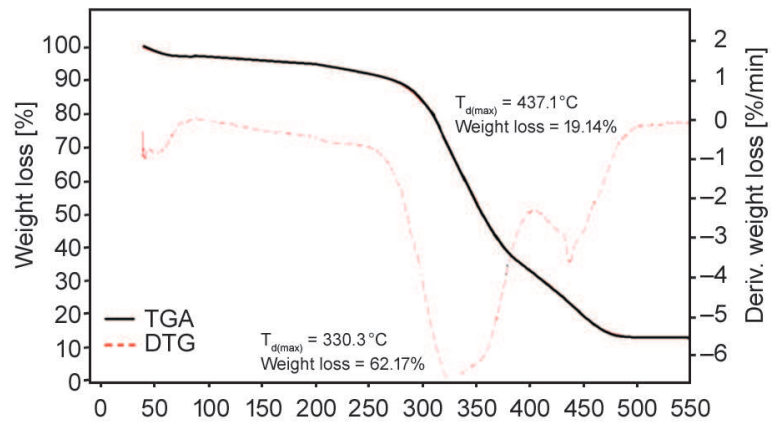

a) $\mathrm{NFC}-3 \quad$ Temperature $\left[{ }^{\circ} \mathrm{C}\right]$
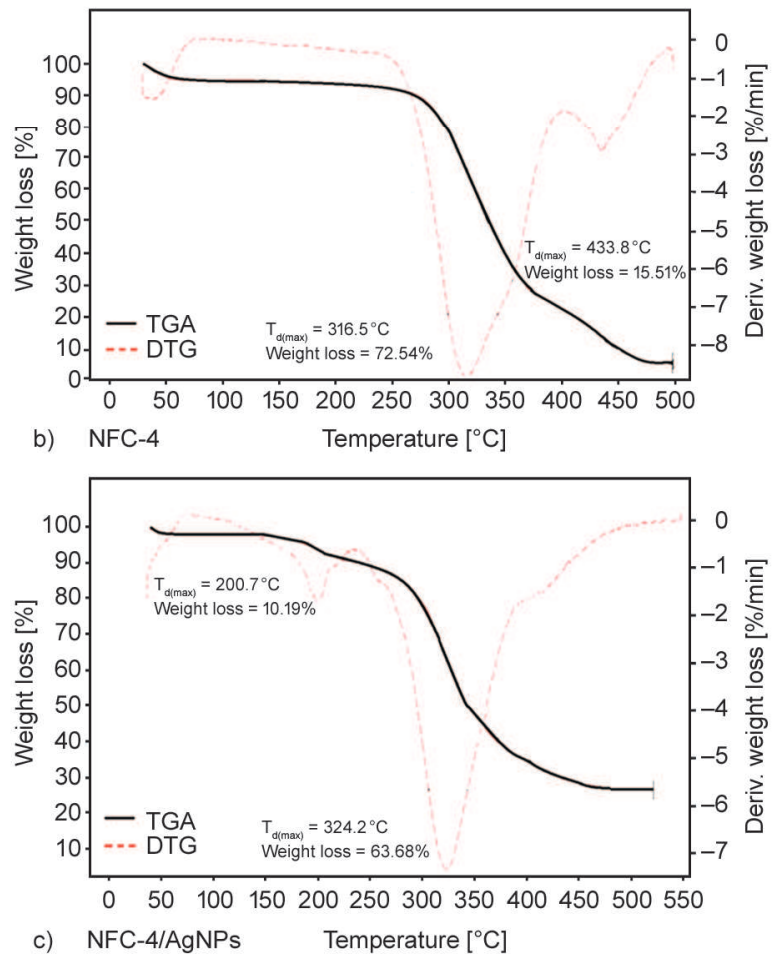

Figure 6. TGA-DTG thermal degradation curves and thermal stability of a) NFC-3, b) NFC-4, and c) NFC-4/ AgNPs (c) nanofibers consisting poly(VP-altMA) copolymer

mal degradation parameters of poly(VP-alt-MA) copolymer based NFCs (cross-linking structures) were also confirmed by DSC analysis (data not shown). DSC results indicated typical curves not including any melting and/or glass-transition peak areas from NFCs for the cross-linked polymer nanofiber structures. The formation of several weak broad exopeaks in the curves of derivative of heat flow versus temperature can be attributed to various chemical reactions formed in the applied isothermal conditions. Thus, the organoclay and AgNPs incorporated PVA/ PVP and poly(VP-alt-MA) as matrix/partner polymer nanocomposite complexes were formed in water solution/dispersed medium due to the easy interaction of silver cations with solvent molecules and reg-

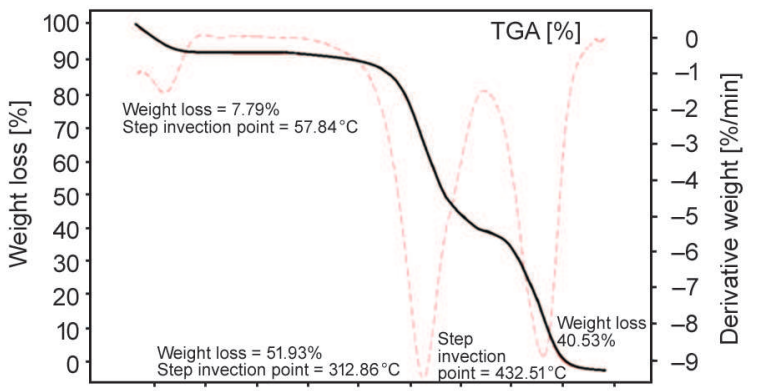

50100150200250300350400450500

a) NFC-1 Temperature $\left[{ }^{\circ} \mathrm{C}\right]$
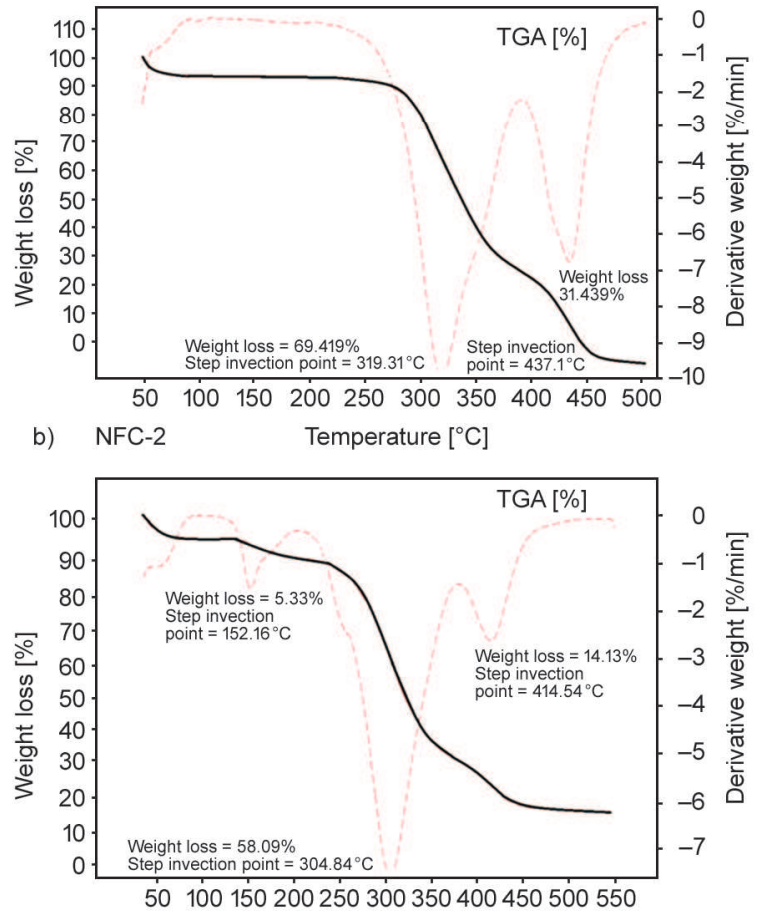

c) NFC-2/AgNPs Temperature $\left[{ }^{\circ} \mathrm{C}\right]$

Figure 7. TGA-DTG thermal degradation curves and thermal stability of a) NFC-1, b) NFC-2 and c) NFC-2/ AgNPs nanofibers consisting PVP homopolymer

ularly repeated free $-\mathrm{COOH},-\mathrm{OH}$ and pyrrolidone $\mathrm{NH}-\mathrm{C}=\mathrm{O}$ groups from partner/matrix polymer chains, as well as exchange reaction with clay cations.

These interactions which took place in the nanofiber structures with dominantly colloidal amorphous areas enhanced with multifunctional sites easily realizing the charge transport process onto the nanofiber surface after the elimination of highest fraction of solvent molecules during electrospinnig. Colloidal structure of nanofibers was due to partially swelling and water-absorption behaviors of matrix PVA polymer and organoclay components in the composites. This interpretation is in reasonable agreement with well know Armand's theory which stated that ionic motion in salt-polymer complex was not due to charges hopping from site to site, but 
also it was a continuous motion occurring in the amorphous region of the polymeric material [46].

\subsection{Thermal behaviors of nanofiber structures consisting PVP (homopolymer)}

Thermal analyses results of PVP containing fiber samples are given in Figure 7. The comparative analysis of TGA-DTG curves from Figure 6 and 7 shows that the thermal degradation parameters were relatively higher in NFCs consisting reactive alternating copolymer as a cross-linker, and predominantly chemical interactions occurred in isothermal growing condition (Figure 6). Unlike this observation, thermal degradation of NFCs consisting PVP (homopolymer) proceeded by two step degradation mechanism without any covalent interactions (Figure 7). Moreover, multi-steps degradations were detected for NFC-2/ AgNPs. Both silver incorporated samples in structurally different systems showed characteristic middle degradation peak at $152-200^{\circ} \mathrm{C}$ relating to decomposition of silver contained complexion linkages.

\subsection{Electrical properties of PVA nanofiber composites with PVP homopolymer nanocomposite and AgNPs}

PVA is a low conducting polymer. However, PVP and various hydrophilic functional copolymers of VP contain ionizable functional groups and units, and they may exhibit high electrical conductive properties. To improve the conductivity of PVA, many researchers used functional polymers as conducting partner polymers. Water solution blend of PVA/PVP showed physical network structure due to hydrogen bonding between $-\mathrm{OH}$ and $-\mathrm{C}=\mathrm{O}$ groups from $\mathrm{PVA}$ and PVP, respectively. The hydrogen bonds are also formed between -OH (PVA) and $\mathrm{Si}-\mathrm{O}$ (silanol of MMT platelets) in PVAMMT clay aqueous suspension $[47,48]$. This unique property improved potential applications of binary polymer systems compared with homopolymers of PVA and PVP [49, 50]. Sengwa and Sankhla [50] synthesized PVA-PVP blend-MMT clay nanocomposite films up to $10 \mathrm{wt} \%$ clay loading by aqueous solution intercalation and melt compounding. Their study revealed that the dielectric constant values of these organic-inorganic nano-composite films can be tuned by loading MMT clay in the polymers matrix, which also improved their physical and thermal properties. Here, we presented a self-assembly approach to fabricate polymer/organoclay nanofiber structures from the binary water solution blends of matrix polymer (PVA), partner polymers (PVP, poly(VP-alt-MA), and Agcarrying matrix/partner nanocomposite complexes) with colloidal dispersed octadecyl amine-MMT clay sheets by green electrospinning nanotechnology. It was proposed that the obtained self-assembled nanostructures could be described as effective electrolyte platforms with higher electrical conductivity, but with lower thermal conductivity due to possible prevention of the transport of thermal energy by interphase nanostructure of clay sheets. To confirm this proposal, effects of composition, origin and fraction of the partner polymers, the organoclay and in situ generated AgNPs on the electrical conductivity properties of nanofiber colloidal electrolytes at various temperatures and pressures were investigated. Electrical conductivity of nanofiber composite films was measured by Equation (3) based on direct current conductivity $\left(\sigma_{\mathrm{dc}}\right)[51]$ :

$$
\sigma_{\mathrm{dc}}=\frac{d}{R A}
$$

where $R$ is a resistance $[\Omega], d$ is a thickness $[\mu \mathrm{m}]$ and $A$ is a surface area $\left(0.25 \mathrm{~cm}^{2}\right)$ as a standard for each testing sample.

Measurement of these parameters was carried out at the different temperatures $\left(22-50^{\circ} \mathrm{C}\right)$ and pressures (around 50-800 Torr). Obtained results given in Figure 8 indicated that the fibers having different compositions (NFC-2, NFC-2/AgNPs and NFC-1) showed higher electrical conductivity $\left(1.0410^{-9}, 8 \cdot 10^{-9}\right.$ and $\left.1.1 \cdot 10^{-9} \mathrm{~S} \cdot \mathrm{cm}^{-1}\right)$ at room temperature as compared with conductivity of pristine PVA $\left(1.25 \cdot 10^{-15} \mathrm{~S} \cdot \mathrm{cm}^{-1}\right)$ [19] (Figure 8a-c). Incorporation of organoclay to nanofiber structures significantly improved the electron interfacial interactions and enhanced conductivity performance of PVA/PVP based nanofiber composites. In a study, PVA/PVP matrix/partner polymer blend composites with volume ratios of 80:20 and 60:40 fabricated by solution casting method showed relatively higher electrical conductivity $\left(2.2 \cdot 10^{-7}\right.$ and $\left.7.3 \cdot 10^{-8} \mathrm{~S} \cdot \mathrm{cm}^{-1}\right)$ at room temperature [21] and at $30^{\circ} \mathrm{C}\left(2.29 \cdot 10^{-7}\right.$ and $\left.5.24 \cdot 10^{-7} \mathrm{~S} \cdot \mathrm{cm}^{-1}\right)$ [23]. Thus incorporation of organoclay ( 5 mass $\%)$ to nanofiber structures significantly improved the electron interfacial interactions and enhanced the conductivity performance of PVA/PVP based nanofiber composites. Several researchers also investigated the effect of organoclay in various polymer nanocompos- 

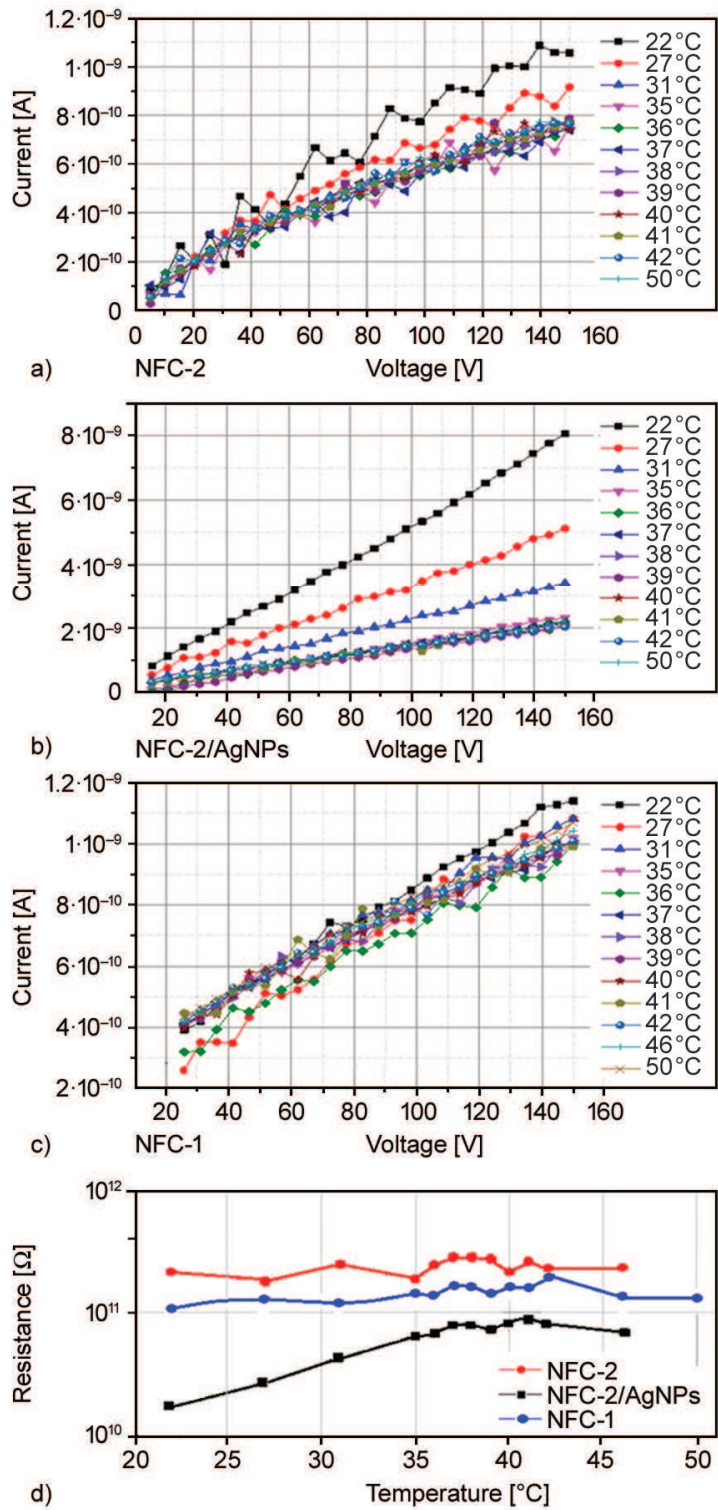

Figure 8. Current (A) versus voltage (V) curves of (a) NFC-2, (b) NFC-2/AgNPs, (c) NFC-1, and (d) their electrical resistance versus temperature curves. Effect of temperature.

ites on electrical conductivity. The hollow spherical morphology of poly(diphenylamine) (PDPA) inside the galleries of montmorillonite organoclay showed different conductive property than PDPA formed by the conventional method due to the confinement effect [52]. Kim et al. [53] evaluated effects of organoMMT clay in the matrix PEO/organoclay nanocomposite electrolytes on the ionic conductivity. They observed that the polymeric electrolyte composites exhibited higher conductivity than pristine $\mathrm{Na}^{+}-$ MMT mineral clay. According to the authors, electrical conductivity of electrolytes depended on the reduced crystallinity and enhanced ion-mobility by the increased interlayer spacing of MMT clay.
Salahuddin et al. [54] reported that the electrical conductivity of polyaniline/organoclay nanocomposites increased 30 times more than that of pristine MMT clay.

\subsection{Electrical properties of PVA nanofiber composites with VP copolymer nanocomposite and AgNPs}

It was suggested that significant covalent bonds could exist between octadecyl amine and partner polymers via amidation of anhydride/carboxyl groups and esterification of anhydride unit with hydroxyl groups in the PVA/PVP (partner-1) and VP copolymer (partner-2) based multifunctional nanofiber composite systems. Comparative analysis results indicated that electrical properties strongly depended on the loaded reactive organoclay and in situ generated AgNPs, which were significantly improved conductivity via accelerating electron transport process. Unlike homopolymer of VP, alternating copolymer of VP containing reactive anhydride units easily interacted with hydroxyl groups of matrix polymer via ringopening intermolecular esterification-crosslinking. NFC-4 nanofiber composites showed excellent conductivity (Figure 9a) and low thermal resistance (Figure 9b) at temperature ranges from 22 to $50^{\circ} \mathrm{C}$ for applied voltages (around 0-2.5 V). This observed phenomenon can be explained by the formation of thermodynamically stable self-assembled negatively charged sites caused by regularly distributed ionized functional groups in alternating partner copolymer. Thus, the ion transport essentially improved in the cross-linked surface structure of the nanofibers. On the other hand, an increase in the fraction of partner copolymer nanocomposite dramatically decreased conductivity (Figure 9c) and increased resistance properties of NFC-3 samples (Figure 9b) because of destroying of the self-assembled and organized ion transfer sites. In conclusion, ratio of applied current $[\mathrm{A}] /$ voltage $[\mathrm{V}]$ and matrix/partner nanocomposites, as well as origin (reactivity) of partner copolymer significantly influenced conductivity and resistance parameters of NFCs. Salamova et al. [55] reported the effect of inorganic salts (co solute) on main parameters of dilute aqueous PVP solutions such as cloud points, phase diagram, low critical solution temperature (LCST) and viscosity. Inclusion of salts into aqueous PVP solution led to the decrease of the LCST and intrinsic viscosity which was caused by the effect of the co solute ions in enhancing 

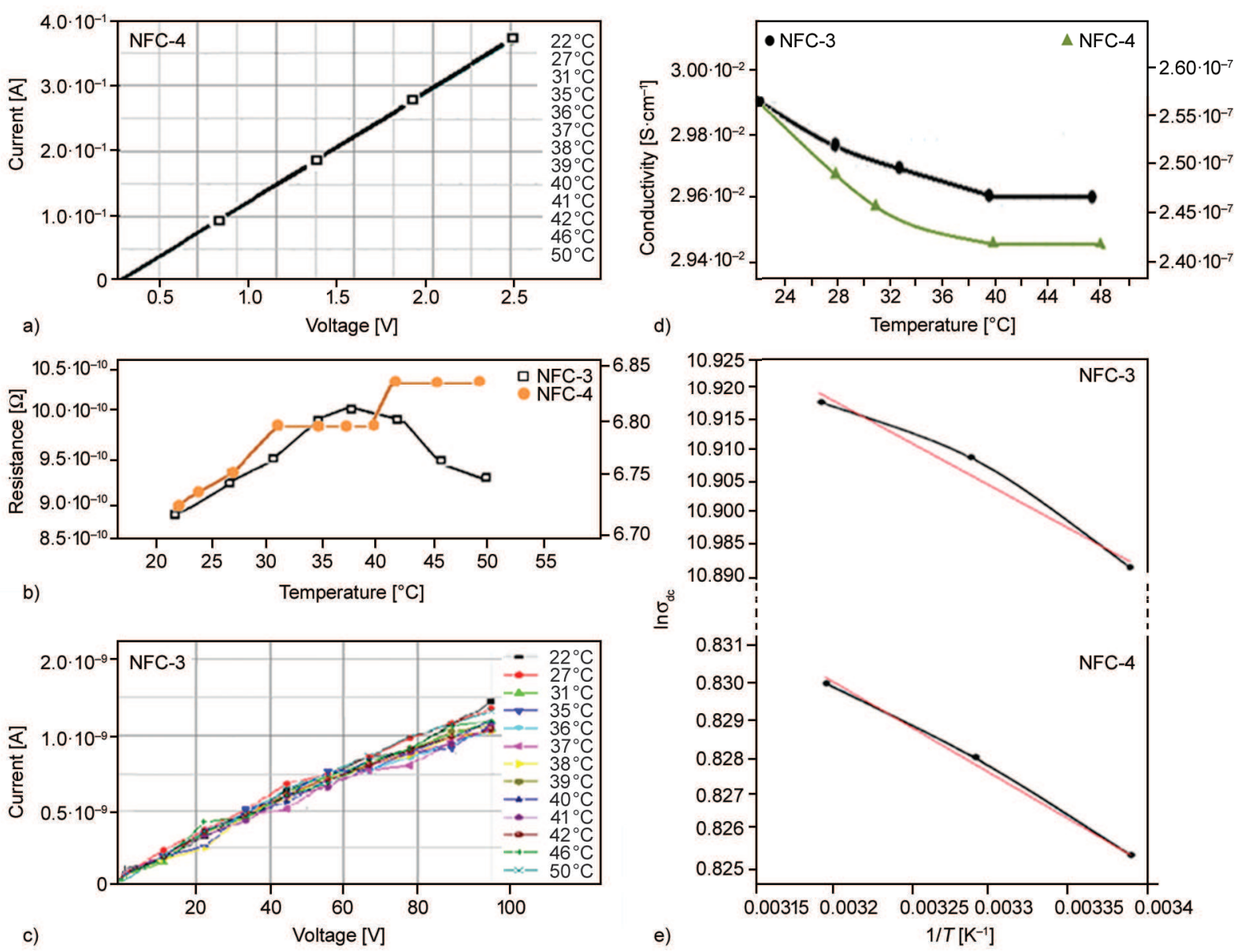

Figure 9. Current versus voltage curves of (a) NFC-4, (c) NFC-3 and (b) their electrical resistance versus temperature; (d) electrical conductivity of NFC-4 and NFC-3 at various temperatures and (e) their activation energy $\left(E_{\mathrm{a}}\right)$ calculated from plots of $\ln \sigma_{\mathrm{dc}}$ versus reciprocal temperature $\left(1 / T\left[\mathrm{~K}^{-1}\right]\right)$. Effect of temperature.

the segment-segment interactions. Cho et al. [56] prepared fiber-based electrical systems based on poly(vinyl alcohol) (PVA) as a fiber forming carrier polymer, poly(styrenesulfonate) (PSS) as a conducting partner polymer, glutaraldehyde as a crosslinker, and negatively charged poly(maleic anhydride-altmethyl vinyl ether) [poly(MA-alt-MVE)] as a doping agent. They found that the cross-linked conducting nanofibers exhibited high conductivity $\left(4-8 \mathrm{~S} \cdot \mathrm{m}^{-1}\right)$. In solid electrolytes, ionic transport is more difficult than electronic charge transport due to the resistance assemblies in the electrode. Resistance, also known as ohmic losses, is due to the losses occurred during ionic and charge transport in amorphous polymer nanofiber electrolyte. It was proposed that the absorption of water molecules in colloidal structure of nanofiber electrolytes with high amorphous area significantly improved ionic charges and their transport, and therefore, increased the conductive sites in polymer nanofiber surface structures. Moreover, these obtained values were very important to evaluate effects of composition, fraction and origin of part- ner polymer nanocomposites and structural factors from the comparative analysis of two series of different nanofibers structures.

Extremely high electrical conductivity of NFC-4 (Figure 9a) compared with other NFCs can be explained by taking into consideration the following structural factors: (1) cross-linking and complexing factors in this NFC played an important role due to providing high degree of electro-active sites on the nanofiber surface, (2) low conductivity of NFC-4/ AgNPs compared with NFC-4 was associated with blocking by silver cations the cross-linking reactions via the formation complexing linkages with hydroxyl groups and salts with carboxyl groups of maleic acid units from partner alternating copolymer, and (3) all other NFCs were prepared from PVA/ PVA polymer systems which were not contained chemically reactive units such as maleic acid, and the formation of electro-active sites was limited by only physical interaction between $\mathrm{OH}$ groups of PVA with pyrrolidone units, as well as $\mathrm{OH}$ groups with octadecyl amine from organoclay. In Figure 9b, 
the temperature dependence of electrical resistivity value did not show a linear increase. NFC-4 showed an increase in resistance up to $30^{\circ} \mathrm{C}$ and saturated up to $40^{\circ} \mathrm{C}$ and then it increased again. Similarly, the electrical resistance of NFC-3 increased up to $37^{\circ} \mathrm{C}$ and it dropped beyond that temperature. These observed phenomena as step inflections in curves, can be related to occurrence of lower sub-glass transition processing, coil-glouble conformational changes of polymer chains, elimination of absorbed water molecules and etc., as well as non-controllable in situ processes in colloidal amorphous medium.

The plots of electrical conductivity versus temperature (Figure 9d) indicated that the conductivities of NFC-3 and NCF-4 only depended on the applied temperature $\left(22-40^{\circ} \mathrm{C}\right)$. Following increase of temperature did not influence the conductivity values. Activation energy $\left(E_{\mathrm{a}}\right)$ can be calculated at above mentioned temperature range by using well-known Arrhenius equation (Equation (4)) [57]. Taking the logarithms of both sides and separating the exponential and pre-exponential terms yields Equation (5). Plots of $l n_{\mathrm{dc}}$ versus $1 / T\left[\mathrm{~K}^{-1}\right]$ given in Figure $9 \mathrm{e}$ clearly indicate that the thermal process follows the Arrhenius equation.

$$
\sigma_{\text {dc }}=\sigma_{0} \mathrm{e}^{-\frac{E_{a}}{R T}}
$$

where $E_{\mathrm{a}}$ is the activation energy, $R$ is the universal gas constant, $\sigma_{0}$ is a temperature-independent constant and $T$ is temperature $[\mathrm{K}]$.

$\ln \sigma_{\mathrm{dc}}=\ln \sigma_{0}-\frac{E_{\mathrm{a}}}{R T}$

The plots showed a linear behavior between $\ln \sigma_{\mathrm{dc}}$ and $1 / T$ and a good fit to the Arrhenius equation. From the plots of $\ln \sigma_{\mathrm{dc}}$ versus $1 / T$ the following activation energy values were calculated: $0.226,0.028$ and $0.022 \mathrm{eV}$ for NFC-4; $0.340,0.076$ and $0.017 \mathrm{eV}$ for NFC-3. The mobility of the charge carriers increased with increasing temperature. Activation energy increased with increasing of the partner copolymer ratio. This can be explained by substantially restricting of the mobility of macromolecular chains in matrix/partner systems via polymer-copolymer covalent cross-linking during electrospinning.

Here, it was also investigated the effect of temperature, pressure and conducting time on the electrical and resistance properties of Ag-incorporated nanofiber composites (NFC-4/AgNPs). According to the results given in Figure 10, applied temperature (Figure 10a) and pressure (Figure 10b) significantly improved conductivity parameters of Ag-carrying NFCs. Comparative analysis at 50 and 760 Torr (Figure 10c and d) showed that an increase in pressure had an effect on the conductivity of the nanofiber composites. Similar effect was also observed for conductivity times. This observation indicated that NFCs were thermodynamically stable covalent crosslinked nanostructures. As resistance had a tendency to decrease with increasing temperature (Figure 10e), the dependence on the pressure tended to decrease (Figure $10 \mathrm{f}$ ). Several researchers reported the effect of pressure on thermal conductivity of various polymer melts, as well as poly(vinyl alcohol) gels $[58,59]$. The thermal conductivity of both amorphous and semi-crystalline polymers was found to increase with increasing applied pressure and generally with increasing temperature. Herein, applied pressure improved the accuracy of in situ physical interactions. This process provided an increase in colloidal amorphous area, the mobility and ion-charge ability of functional groups from the nanofibrous structures. It was proposed that the use of pressure improved accuracy of electro-active sites due to increased temperature and across transition temperature, as well as increase of colloidal amorphous area, mobility of functional groups from fibrous structures, which significantly improved the electrical conductivity of polymer nanofiber composites.

\section{Conclusions}

This work presented a new approach to fabricate novel multifunctional nanofiber electrolytes with linear and cross-linked polymer structures by using PVA + ODA-MMT (matrix), PVP homopolymer + ODA-MMT (partner-1), poly(VP-alt-MA) + ODAMMT (partner-2) and Ag-carrying matrix/polymer system with varying the fraction of partner (co) polymers in nanofiber composites. Morphology and electrical properties strongly depended on the origin and fraction of partner polymer NFCs. Covalent cross-linked nanofiber structures significantly increased the conductivity and thermal behaviors of NFCs. Ag-carrying polymer complexes and in situ generated AgNPs onto nanofiber surfaces accelerated phase separation process and considerably enhanced the electrical parameters of NFCs. A covalent bridge of partner alternating copolymer between PVA macromolecules not only reinforced the network 

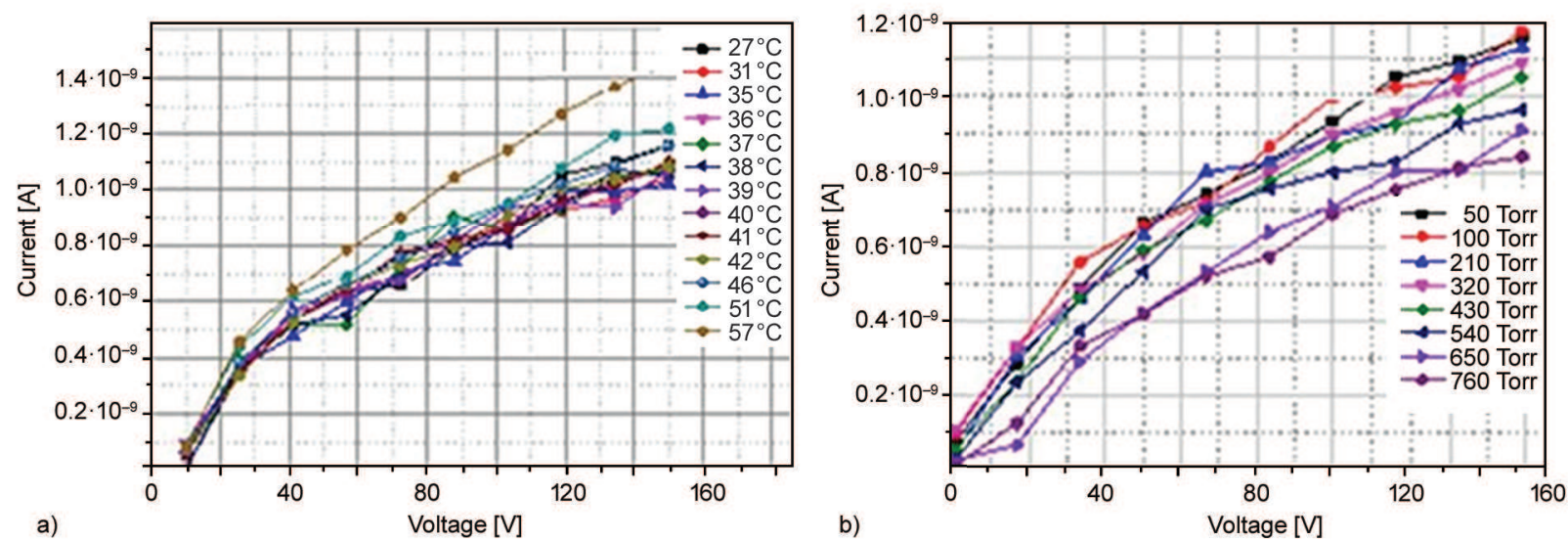

a) Voltage [V]

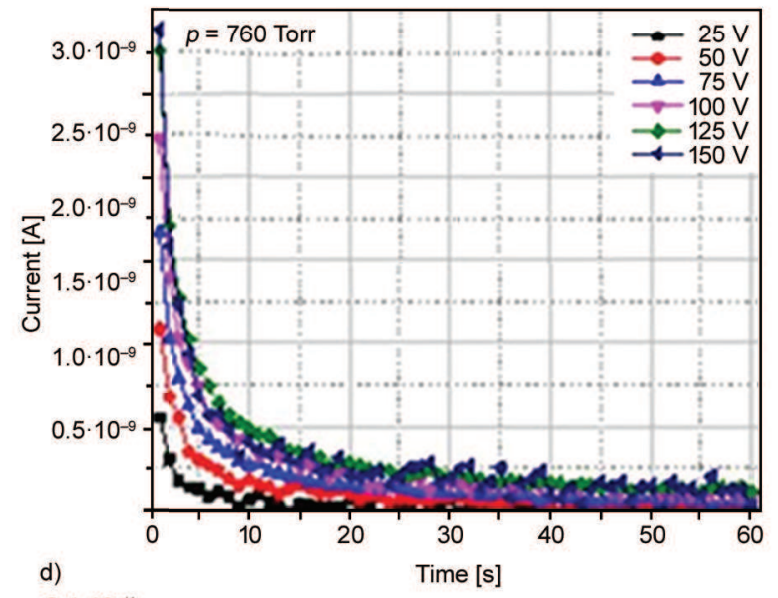

c)
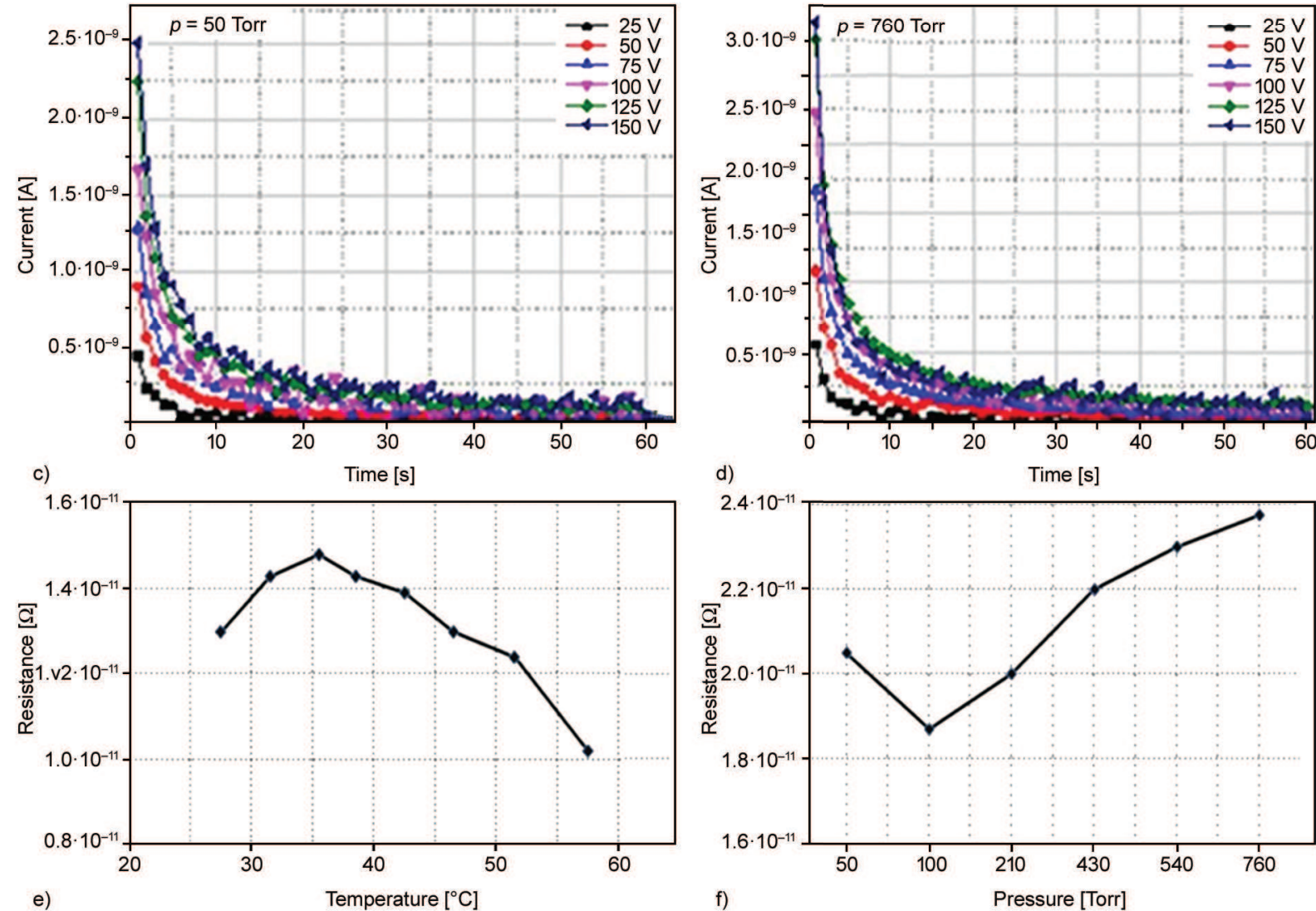

Figure 10. Electrical conductivity and resistance of NFC-4/AgNPs nanofiber composite. Effects of a) temperature, b) pressure, and conduct times at c) 50 Torr and d) 760 Torr on electrical conductivity; effects of e) temperature and f) pressure on resistance

but also provided extra ion charge transport sites due to its regularly repeated functional monomer units onto polymer chains. High and excellent behaviors were observed for the homopolymer and copolymer of VP based fiber structures, respectively. The obtained green nanomaterials with unique properties and higher contact areas can open new avenue for various applications in microelectronics, sensor devices, electrochemical processing, fuel cell, nanolithography and power technologies, as well as in various bioengineering processing as a reactive platform.

\section{Acknowledgements}

The authors would like to acknowledge Turkish Scientific and Technological Research Council (TUBITAK) for the financial support through postdoctoral projects TBAGHD/249 and BIDEBPD/2218.

\section{References}

[1] Agarwal S., Greiner A., Wendorff J. H.: Functional materials by electrospinning of polymers. Progress in Polymer Science, 38, 963-991 (2013).

DOI: $10.1016 /$ j.progpolymsci.2013.02.001 
[2] Cai Y., Zong X., Ban H., Liu Q., Qiao H., Wei Q., Zhao Y., Fong H.: Fabrication, structural morphology and thermal energy storage/retrieval of ultrafine phase change fibres consisting of polyethylene glycol and polyamide 6 by electrospinning. Polymers \& Polymer Composites, 21, 525-532 (2013).

[3] Sahay R., Kumar P. S., Sridhar R., Sundaramurthy J., Venugopal J., Mhaisalkar S. G., Ramakrishna S.: Electrospun composite nanofibers and their multifaceted applications. Journal of Materials Chemistry, 22, 12953-12971 (2012).

DOI: $10.1039 / \mathrm{C} 2 J M 30966 \mathrm{~A}$

[4] Cui W-W., Tang D-Y., Gong Z-L.: Electrospun poly (vinylidene fluoride)/poly(methyl methacrylate) grafted $\mathrm{TiO}_{2}$ composite nanofibrous membrane as polymer electrolyte for lithium-ion batteries. Journal of Power Sources, 223, 206-213 (2013).

DOI: 10.1016/j.jpowsour.2012.09.049

[5] Abdelgawad A. M., Hudson S. M., Rojas O. J.: Antimicrobial wound dressing nanofiber mats from multicomponent (chitosan/silver-NPs/polyvinyl alcohol) systems. Carbohydrate Polymers, 100, 166-178 (2014).

DOI: $10.1016 / \mathrm{j}$.carbpol.2012.12.043

[6] Um-i-Zahra S., Shen X. X., Li H., Zhu L.: Study of sustained release drug-loaded nanofibers of cellulose acetate and ethyl cellulose polymer blends prepared by electrospinning and their in-vitro drug release profiles. Journal of Polymer Research, 21, 602-614 (2014). DOI: $10.1007 / \mathrm{s} 10965-014-0602-5$

[7] Nataraj S. K., Yang K. S., Aminabhavi T. M.: Polyacrylonitrile-based nanofibers - A state-of-the-art review. Progress in Polymer Science, 37, 487-513 (2012). DOI: $10.1016 /$ j.progpolymsci.2011.07.001

[8] Pham Q. P., Sharma U., Mikos A. G. M.: Electrospinning of polymeric nanofibers for tissue engineering applications: A review. Tissue Engineering, 12, $1197-$ 1211 (2006).

DOI: $10.1089 /$ ten.2006.12.1197

[9] Zhang G., Kataphinan W., Teye-Mensah R., Katta P., Khatri L., Evans E. A., Chase G. G., Ramsier R. D., Reneker D. H.: Electrospun nanofibers for potential space-based applications. Materials Science and Engineering: B, 116, 353-358 (2005).

DOI: $10.1016 /$ j.mseb.2004.05.050

[10] Taepaiboon P., Rundsardthong U., Supaphol P.: Drugloaded electrospun mats of poly(vinyl alcohol) fibres and their release characteristics of four model drugs. Nanotechnology, 17, 2317-2329 (2006).

DOI: $10.1088 / 0957-4484 / 17 / 9 / 041$

[11] Jannesari M., Varshosaz J., Morshed M., Zamani M.: Composite poly(vinyl alcohol)/poly(vinyl acetate) electrospun nanofibrous mats as a novel wound dressing matrix for controlled release of drugs. International Journal of Nanomedicine, 6, 993-1003 (2011). DOI: $\underline{10.2147 / \text { IJN.S17595 }}$
[12] Strawhecker K. E., Manias E.: Structure and properties of poly(vinyl alcohol)/ $\mathrm{Na}^{+}$montmorillonite nanocomposites. Chemistry of Materials, 12, 2943-2949 (2000). DOI: $10.1021 / \mathrm{cm} 000506 \mathrm{~g}$

[13] Chang J-H., Jang T-G., Ihn K. J., Lee W-K., Sur G. S.: Poly(vinyl alcohol) nanocomposites with different clays: Pristine clays and organoclays. Journal of Applied Polymer Science, 90, 3208-3214 (2003).

DOI: $10.1002 /$ app. 12996

[14] Khan W. S., Asmatulu R., Eltabey M. M.: Electrical and thermal characterization of electrospun PVP nanocomposite fibers. Journal of Nanomaterials, 2013, 160931/1160931/9 (2013).

DOI: $10.1155 / 2013 / 160931$

[15] Georgiev G., Konstantinov C., Kabaivanov V.: The role of the charge-transfer complex during the copolymerization of $\mathrm{N}$-vinylpyrrolidone and maleic anhydride. Macromolecules, 25, 6302-6308 (1992).

DOI: $10.1021 / \mathrm{ma} 00049 \mathrm{a} 029$

[16] Bacu E., Chitanu G. C., Couture A., Grandclaudon P., Singurel G., Carpov A.: Potential drug delivery systems from maleic anhydride copolymers and phenothiazine derivatives. European Polymer Journal, 38, 15091513 (2002).

DOI: 10.1016/S0014-3057(02)00040-X

[17] Veron L., Revol M., Mandrand B., Delair T.: Synthesis and characterization of poly(N-vinyl pyrrolidone-altmaleic anhydride): Conjugation with bovine serum albumin. Journal of Applied Polymer Science, 81, 33273337 (2001).

DOI: $10.1002 /$ app. 1789

[18] Temiz A., Toğay S. O., Şener A., Güven G., Rzaev Z. M. O., Piskin E.: Antimicrobial poly(N-vinyl-2-pyrrolidone-alt-maleic anhydride)/poly(ethylene imine) macrocomplexes. Journal of Applied Polymer Science 102, 5841-5847 (2006).

DOI: $10.1002 / a p p .24903$

[19] Ahmad Zamri M. F. M., Sharif Zein S. H., Abdullah A. Z., Basir N. I.: Improved electrical conductivity of polyvinyl alcohol/multiwalled carbon nanotube nanofibre composite films with $\mathrm{MnO}_{2}$ as filler synthesised using the electrospinning process. International Journal of Engineering and Technology, 11, 20-26 (2011).

[20] Ravi M., Kumar K. K., Rao V. V. R. N.: Investigation on electrical and dielectric properties of PVP: KCLO (4) polymer electrolyte films. Indian Journal of Pure and Applied Physics, 51, 362-366 (2013).

[21] Hatta F. F., Yahya M. Z. A., Ali A. M. M., Subban R. H. Y., Harun M. K., Mohamad A. A.: Electrical conductivity studies on PVA/PVP-KOH alkaline solid polymer blend electrolyte. Ionics, 11, 418-422 (2005). DOI: 10.1007/BF02430259

[22] Inzelt G., Pineri M., Schultze J. W., Vorotyntsev M. A.: Electron and proton conducting polymers: Recent developments and prospects. Electrochimica Acta, 45, 2403-2421 (2000). DOI: $10.1016 / \mathrm{S} 0013-4686(00) 00329-7$ 
[23] Rajeswari N., Selvasekarapandian S., Karthikeyan S., Prabu M., Hirankumar G., Nithya H., Sanjeeviraja C.: Conductivity and dielectric properties of polyvinyl alcohol-polyvinylpyrrolidone poly blend film using nonaqueous medium. Journal of Non-Crystalline Solids, 357, 3751-3756 (2011).

DOI: 10.1016/j.jnoncrysol.2011.07.037

[24] Datta R. S., Said S. M., Shahrir S. R., Abdullah N., Sabri M. F. M., Balamurugan S., Miyazaki Y., Hayashi K., Hashim N. A., Habiba U., Afifi A. M.: Ionic liquid entrapment by an electrospun polymer nanofiber matrix as a high conductivity polymer electrolyte. RSC Advances, 5, 48217-48223 (2015).

DOI: $10.1039 / \mathrm{C} 5 \mathrm{RA03935E}$

[25] Laforgue A., Robitaille L., Mokrini A., Ajji A.: Fabrication and characterization of ionic conducting nanofibers. Macromolecular Materials and Engineering, 292, 1229-1236 (2007). DOI: $10.1002 /$ mame.200700200

[26] Lu X., Zhou J., Zhao Y., Qiu Y., Li J.: Room temperature ionic liquid based polystyrene nanofibers with superhydrophobicity and conductivity produced by electrospinning. Chemistry of Materials, 20, 3420-3424 (2008).

DOI: $10.1021 / \mathrm{cm} 800045 \mathrm{~h}$

[27] Pisesweerayos P., Dangtip S., Supaphol P., Srikhirin T.: Conductive nanocomposite aligned fibers of PVAAgNPs-PEDOT/PSS. Advanced Materials Research, 1033-1034, 1009-1019 (2014).

DOI: 10.4028/www.scientific.net/AMR.1033-1034.1009

[28] Manoratne C. H., Rajapakse R. M. G., Dissanayake M. A. K. L.: Ionic conductivity of poly(ethylene oxide) (PEO)-montmorillonite (MMT) nanocomposites prepared by intercalation from aqueous medium. International Journal of Electrochemical Science, 1, 32-46 (2006).

[29] Ravindran A., Chandran P., Khan S. S.: Biofunctionalized silver nanoparticles: Advances and prospects. Colloids and Surfaces B: Biointerfaces, 105, 342-352 (2013).

DOI: $10.1016 /$ j.colsurfb.2012.07.036

[30] Ilker M. F., Nüsslein K., Tew G. N., Coughlin E. B.: Tuning the hemolytic and antibacterial activities of amphiphilic polynorbornene derivatives. Journal of the American Chemical Society, 126, 15870-15875 (2004).

DOI: $10.1021 / \mathrm{ja} 045664 \mathrm{~d}$

[31] Sambhy V., MacBride M. M., Peterson B. R., Sen A.: Silver bromide nanoparticle/polymer composites: Dual action tunable antimicrobial materials. Journal of the American Chemical Society, 128, 9798-9808 (2006). DOI: $10.1021 / \mathrm{ja} 061442 \mathrm{z}$
[32] Galya T., Sedlařík V., Kuřitka I., Novotný R., Sedlaříková J., Sáha P.: Antibacterial poly(vinyl alcohol) film containing silver nanoparticles: Preparation and characterization. Journal of Applied Polymer Science, 110, 3178-3185 (2008).

DOI: $10.1002 /$ app. 28908

[33] Hong K. H., Park J. L., Sul I. H., Youk J. H., Kang T. J.: Preparation of antimicrobial poly(vinyl alcohol) nanofibers containing silver nanoparticles. Journal of Polymer Science Part B: Polymer Physics, 44, 2468-2474 (2006).

DOI: $10.1002 /$ polb.20913

[34] Nguyen T-H., Lee K-H., Lee B-T.: Fabrication of Ag nanoparticles dispersed in PVA nanowire mats by microwave irradiation and electro-spinning. Materials Science and Engineering: C, 30, 944-950 (2010). DOI: $10.1016 / \mathrm{j} . \mathrm{msec} .2010 .04 .012$

[35] Pollo L. D., Duarte L. T., Anacleto M., Habert A. C., Borges C. P.: Polymeric membranes containing silver salts for propylene/propane separation. Brazilian Journal of Chemical Engineering, 29, 307-314 (2012). DOI: 10.1590/S0104-66322012000200011

[36] Shukur M. F., Ithnin R., Sonsudin F., Yahya R., Ahmad Z., Kadir M. F. Z.: Conduction mechanism and dielectric properties of solid biopolymer electrolyte incorporated with silver nitrate. Advanced Materials Research, 701, 115-119 (2013).

DOI: 10.4028/www.scientific.net/AMR.701.115

[37] Suthanthiraraj S. A., Kumar R., Paul B. J.: Impact of $\mathrm{ZrO}_{2}$ nanoparticles on ionic transport and electrochemical properties of nanocomposite gel polymer electrolyte: PPG (4000)- $\mathrm{AgCF}_{3} \mathrm{SO}_{3}: \mathrm{ZrO}_{2}$. International Journal of Nanoscience, 10, 241-246 (2011). DOI: $10.1142 / \mathrm{S} 0219581 \mathrm{X} 11007855$

[38] Rzayev Z. M. O., Şimşek M., Bunyatova U., Salamov B.: Novel colloidal nanofiber semiconductor electrolytes from solution blends of PVA/ODA-MMT, poly(itaconic anhydride-alt-2-vinyl-1,3-dioxalan) and its Agcarrying polymer complex by reactive electrospinning. Colloids and Surfaces A: Physicochemical and Engineering Aspects, 492, 26-37 (2016). DOI: $10.1016 /$ j.colsurfa.2015.12.011

[39] Dhakal T. R., Mishra S. R., Glenn Z., Rai B. K.: Synergistic effect of PVP and PEG on the behavior of silver nanoparticle-polymer composites. Journal of Nanoscience and Nanotechnology, 12, 6389-6396 (2012). DOI: 10.1166/jnn.2012.6561

[40] Jin W-J., Lee H. K., Jeong E. H., Park W. H., Youk J. H.: Preparation of polymer nanofibers containing silver nanoparticles by using poly(N-vinylpyrrolidone). Macromolecular Rapid Communications, 26, 19031907 (2005).

DOI: $\underline{10.1002 / \text { marc. } 200500569}$ 
[41] Lambert J. B., Shurvell H. F., Verbit L., Cooks R. G., Stout G. H.: Organic structural analysis. Collier Macmillan, London (1976).

[42] Jenkins R., Snyder R. L.: Introduction to X-ray powder diffractometry. Wiley, New York (1996).

[43] Rzayev Z. M. O., Şenol B., Denkbaş E. B.: Functional copolymer/organo-montmorillonite nanoarchitectures. IX. Synthesis and nanostructure-morphology-thermal behaviour relationships of poly[(maleic anhydride)alt-(acrylic acid)]/organo- montmorillonite nanocomposites. Polymer International, 60, 1446-1454 (2011). DOI: 10.1002/pi.3099

[44] Li G., He D., Qian B., Guan B., Gao S., Cui Y., Yokoyama K., Wang L.: Fungus-mediated green synthesis of silver nanoparticles using Aspergillus terreus. International Journal of Molecular Sciences, 13, 466476 (2012).

DOI: $10.3390 /$ ijms 13010466

[45] Peppas N. A., Tennenhouse D.: Semicrystalline poly (vinyl alcohol) films and their blends with poly(acrylic acid) and poly(ethylene glycol) for drug delivery applications. Journal of Drug Delivery Science and Technology, 14, 291-297 (2004).

DOI: $10.1016 / \mathrm{S} 1773-2247(04) 50050-3$

[46] Berthier C., Gorecki W., Minier M., Armand M. B., Chabagno J. M., Rigaud P.: Microscopic investigation of ionic conductivity in alkali metal salts-poly(ethylene oxide) adducts. Solid State Ionics, 11, 91-95 (1983). DOI: 10.1016/0167-2738(83)90068-1

[47] İşci S., Günister E., Ece O. T., Güngör N.: The modification of rheologic properties of clays with PVA effect. Materials Letters, 58, 1975-1978 (2004). DOI: 10.1016/j.matlet.2004.01.001

[48] Jung H. M., Lee E. M., Ji B. C., Deng Y., Yun J. D., Yeun J. H.: Poly(vinyl acetate)/poly(vinyl alcohol)/ montmorillonite nanocomposite microspheres prepared by suspension polymerization and saponification. Colloid and Polymer Science, 285, 705-710 (2007). DOI: $10.1007 / \mathrm{s} 00396-006-1623-3$

[49] Sengwa R. J., Sankhla S., Choudhary S.: Dielectric characterization of solution intercalation and melt intercalation poly(vinyl alcohol)-poly(vinylpyrrolidone) blendmontmorillonite clay nanocomposite films. Indian Journal of Pure and Applied Physics, 48, 196-204 (2010).

[50] Sengwa R. J., Sankhla S.: Dielectric dispersion study of coexisting phases of aqueous polymeric solution: Poly(vinyl alcohol) + poly(vinyl pyrrolidone) twophase systems. Polymer, 48, 2737-2744 (2007). DOI: $10.1016 /$ j.polymer.2007.03.030
[51] Kamoun E. A., Youssef M. E., Abu-Saied M. A., Fahmy A., Khalil H. F., Abdelhai F.: Ion conducting nanocomposite membranes based on PVA-HA-HAP for fuel cell application: II. Effect of modifier agent of PVA on membrane properties. Interantional Juornal of Electrochemical Science, 10, 6627-6644 (2015).

[52] Gopalan A. I., Lee K-P., Hong M-H., Santhosh P., Manesh K. M., Kim S-H.: Nanostructuring of poly(diphenylamine) inside the galleries of montmorillonite organo clay through self-assembly approach. Journal of Nanoscience and Nanotechnology, 6, 1594-1601 (2006).

DOI: $10.1166 /$ jnn.2006.240

[53] Kim S., Hwang E-J., Jung Y., Han M., Park S-J.: Ionic conductivity of polymeric nanocomposite electrolytes based on poly(ethylene oxide) and organo-clay materials. Colloids and Surfaces A: Physicochemical and Engineering Aspects, 313-314, 216-219 (2008). DOI: $10.1016 /$ j.colsurfa.2007.04.097

[54] Salahuddin N., Ayad M. M., Ali M.: Synthesis and characterization of polyaniline-organoclay nanocomposites. Journal of Applied Polymer Science, 107, 19811989 (2008). DOI: $10.1002 / a p p .27180$

[55] Salamova U., Rzaev Z. M. O., Altindal Ş., Masimov A. A.: Effect of inorganic salts on the main parameters of the dilute aqueous poly(vinylpyrrolidone) solutions. Polymer, 37, 2415-2421 (1996). DOI: $10.1016 / 0032-3861(96) 85353-5$

[56] Cho D., Hoepker N., Frey M. W.: Fabrication and characterization of conducting polyvinyl alcohol nanofibers. Materials Letters, 68, 293-295 (2012). DOI: $10.1016 /$ j.matlet.2011.10.109

[57] Schwaab M., Pinto J. C.: Optimum reference temperature for reparameterization of the Arrhenius equation. Part 1: Problems involving one kinetic constant. Chemical Engineering Science, 62, 2750-2764 (2007).

DOI: $10.1016 /$ j.ces.2007.02.020

[58] Andersson O., Johari G. P.: Effect of pressure on thermal conductivity and pressure collapse of ice in a polymer-hydrogel and kinetic unfreezing at $1 \mathrm{GPa}$. Journal of Chemical Physics, 134, 124903/1-124903/10 (2011). DOI: $10.1063 / 1.3568817$

[59] Dawson A., Rides M., Nottay J.: The effect of pressure on the thermal conductivity of polymer melts. Polymer Testing, 25, 268-275 (2006).

DOI: $10.1016 /$ j.polymertesting.2005.10.001 